\title{
Quality-Assurance Plan for the Analysis of Suspended Sediment by the U.S. Geological Survey in Montana
}

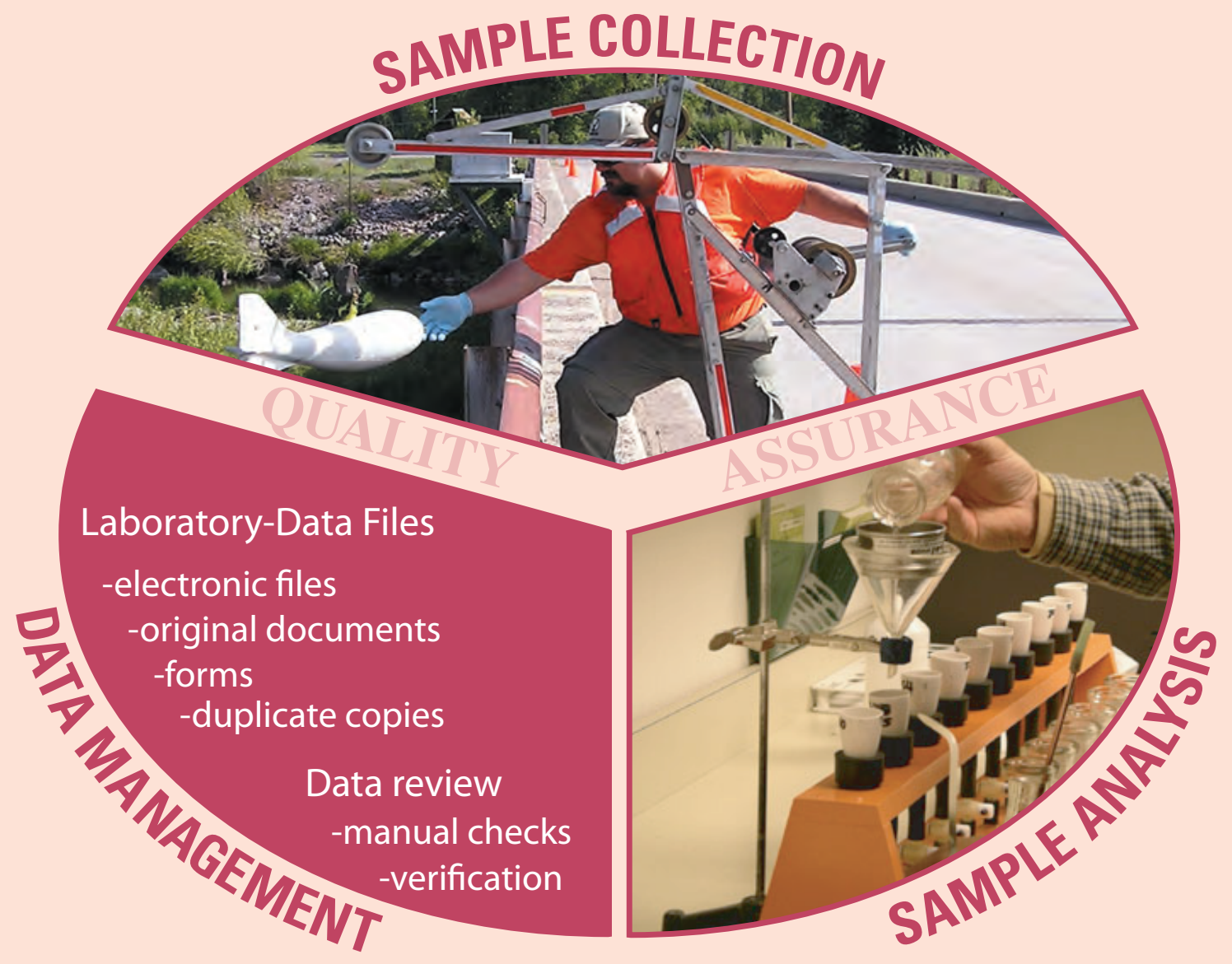

Open-File Report 2006-1242 
COVER PHOTOGRAPHS: Top: Collecting suspended-sediment sample at Clark Fork at Turah Bridge, near Bonner, Mont. Photograph by Kent A. Dodge, U.S. Geological Survey, taken June 2, 2004.

Bottom right: Processing suspended-sediment sample through a sieve to determine the percentage of sediment mass finer than 0.062-millimeter diameter (silt size and smaller). Photograph by Kent A. Dodge, U.S. Geological Survey, taken January 17, 2002. 


\section{Quality-Assurance Plan for the Analysis of Suspended Sediment by the U.S. Geological Survey in Montana}

By Kent A. Dodge and John H. Lambing

Open-File Report 2006-1242 


\section{U.S. Department of the Interior DIRK KEMPTHORNE, Secretary \\ U.S. Geological Survey \\ P. Patrick Leahy, Acting Director}

\section{U.S. Geological Survey, Reston, Virginia: 2006}

For product and ordering information:

World Wide Web: http://www.usgs.gov/pubprod

Telephone: 1-888-ASK-USGS

For more information on the USGS--the Federal source for science about the Earth, its natural and living resources, natural hazards, and the environment:

World Wide Web: http://www.usgs.gov

Telephone: 1-888-ASK-USGS

Any use of trade, product, or firm names is for descriptive purposes only and does not imply endorsement by the U.S. Government.

Although this report is in the public domain, permission must be secured from the individual copyright owners to reproduce any copyrighted materials contained within this report.

Suggested citation:

Dodge, K.A., and Lambing, J.H., 2006, Quality-assurance plan for the analysis of suspended sediment by the U.S. Geological Survey in Montana: U.S. Geological Survey Open-File Report 2006-1242, 25 p. 


\section{Contents}

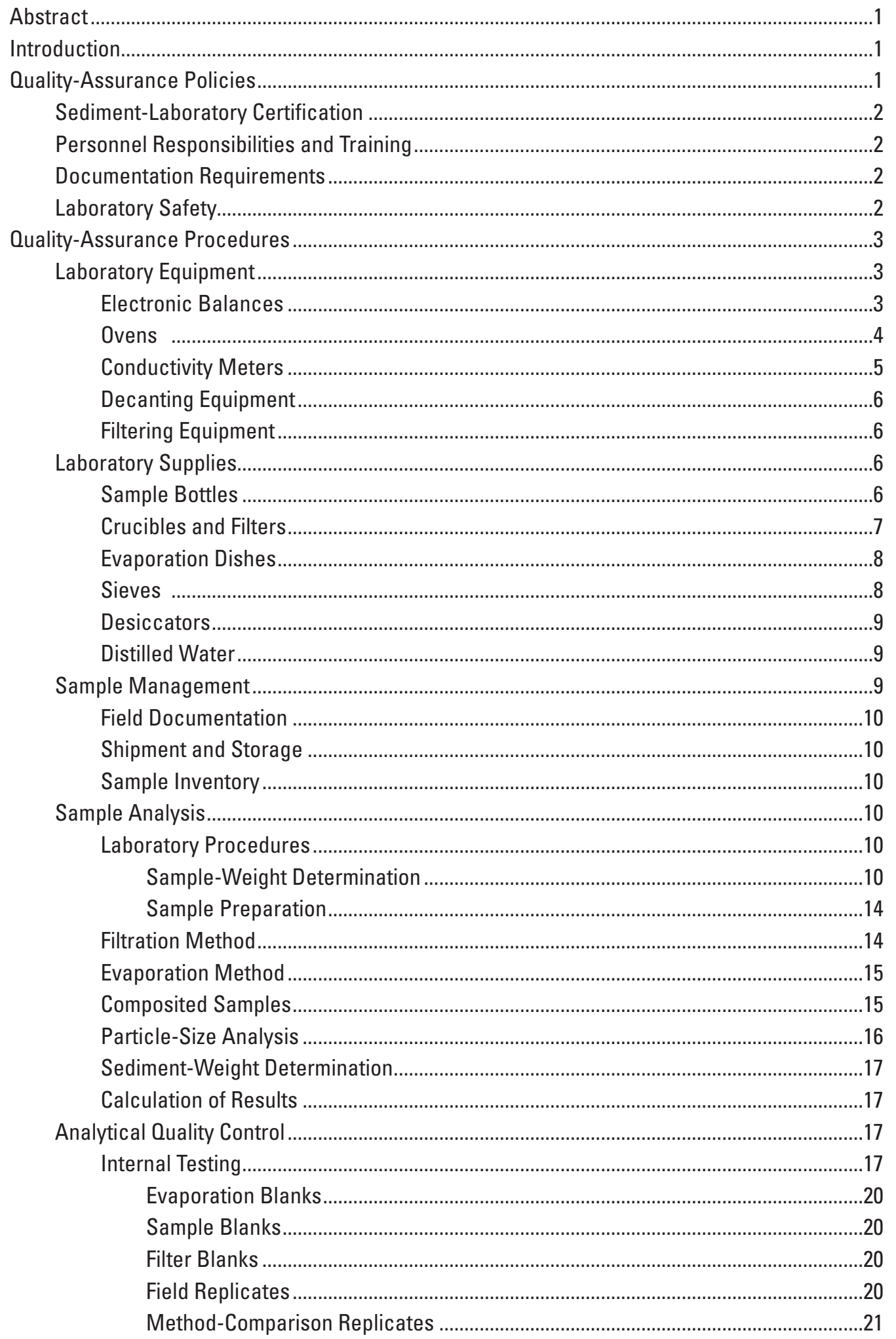




\title{
Contents-Continued
}

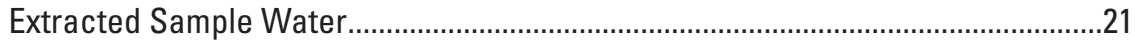

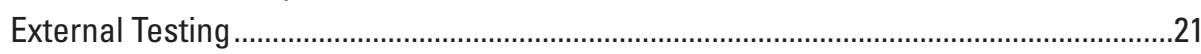 \\ Sediment Laboratory Quality-Assurance Program ................................................21

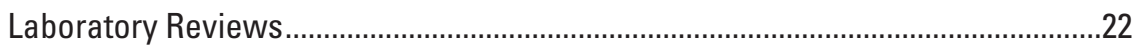

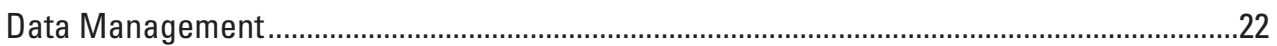

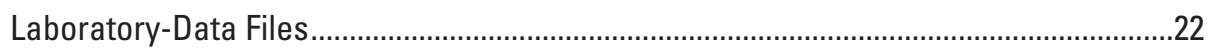

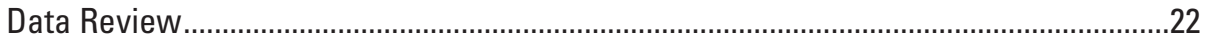

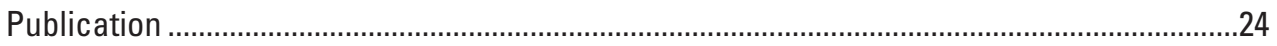

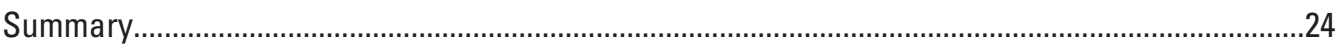

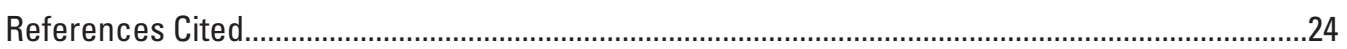

\section{Figures}

1-6. Photographs showing:

1. Analytical balance electronically connected to laboratory computer terminal.......4

2. Mechanical-convection oven for drying sediment in evaporation dishes ................5

3. Convection oven for drying sediment in crucibles .................................................6

4. Vacuum-hose system and workbench for decanting water from suspended-sediment samples................................................................................

5. Manifold for vacuum filtration of suspended-sediment samples through crucibles

6. Suspended-sediment sample poured through a 0.062-millimeter sieve to separate sand from fine sediment

7. Example of a water-quality field form used to document information about water-quality samples collected by U.S. Geological Survey personnel

8. Example of a sediment-sample field form used to document information about suspended-sediment samples collected by observers.

9. Flow chart showing operational sequence for the analysis of suspended-sediment samples in the Montana Sediment Laboratory.

10. Example of an analytical request form used to document information about sediment samples shipped to the U.S. Geological Survey lowa Sediment Laboratory.....

11. Example of a form used to document information about sediment-data distribution in the USGS Montana Water Science Center.

\section{Table}

1. Factors for converting suspended-sediment concentration from parts per million to milligrams per liter. 


\section{Conversion Factors, Abbreviated Water-quality Units, and Acronyms}

\begin{tabular}{lcl}
\hline Multiply & By & To obtain \\
\hline centimeter $(\mathrm{cm})$ & 0.3937 & inch (in.) \\
meter $(\mathrm{m})$ & 3.281 & foot $(\mathrm{ft})$ \\
gram $(\mathrm{g})$ & 0.03527 & ounce $(\mathrm{oz})$ \\
gram per cubic centimeter $\left(\mathrm{g} / \mathrm{cm}^{3}\right)$ & 0.03613 & pound per cubic inch $\left(\mathrm{lb} / \mathrm{in} .^{3}\right)$ \\
kilogram per square centimeter $\left(\mathrm{kg} / \mathrm{cm}^{2}\right)$ & 28.96 & inch of mercury at $60^{\circ} \mathrm{F}(\mathrm{in} \mathrm{Hg})$ \\
liter $(\mathrm{L})$ & 0.2642 & gallon $(\mathrm{gal})$ \\
liter per minute $(\mathrm{L} / \mathrm{min})$ & 0.2642 & gallon per minute $(\mathrm{gal} / \mathrm{min})$ \\
milliliter $(\mathrm{mL})$ & 0.06102 & cubic inch $\left(\mathrm{in} .^{3}\right)$ \\
millimeter $(\mathrm{mm})$ & 0.03937 & inch (in.) \\
Watt $(\mathrm{W})$ & 0.001340 & horsepower $(\mathrm{hp})$ \\
\hline
\end{tabular}

Temperature in degrees Celsius $\left({ }^{\circ} \mathrm{C}\right)$ can be converted to degrees Fahrenheit $\left({ }^{\circ} \mathrm{F}\right)$ as follows:

${ }^{\circ} \mathrm{F}=\left(1.8 \mathrm{x}^{\circ} \mathrm{C}\right)+32$

\section{Abbreviated water-quality units used in this report:}

$\mu \mathrm{S} / \mathrm{cm}$ microsiemens per centimeter at 25 degrees Celsius $\left(\mu \mathrm{S} / \mathrm{cm}\right.$ at $\left.25^{\circ} \mathrm{C}\right)$

$\mathrm{mg} / \mathrm{L} \quad$ milligrams per liter

ppm parts per million

\section{Acronyms used in this report:}

CVO Cascades Volcano Observatory, Vancouver, Wash.

EDI Equal Discharge Increment

NWIS National Water Information System

SLEDS Sediment Laboratory Environmental Data System

SLOA Sediment Laboratory Quality-Assurance Program

USGS U.S. Geological Survey

WRD Water Resources Discipline of the U.S. Geological Survey 



\title{
Quality-Assurance Plan for the Analysis of Suspended Sediment by the U.S. Geological Survey in Montana
}

\author{
By Kent A. Dodge and John H. Lambing
}

\begin{abstract}
A quality-assurance plan has been developed for use by the sediment laboratory of the U.S. Geological Survey Montana Water Science Center in conducting activities related to the analysis of suspended sediment. The plan documents quality-assurance policies for sediment-laboratory certification, personnel responsibilities and training, documentation requirements, and laboratory safety. The plan also documents quality-assurance procedures related to laboratory equipment and supplies, sample management, sample analysis, analytical quality control, and data management.
\end{abstract}

\section{Introduction}

Suspended-sediment samples are routinely collected from streams and analyzed for concentration and particlesize distribution by the U.S. Geological Survey (USGS) in response to various data-collection objectives. The procedures used to collect these samples are described in reports by Guy and Norman (1970), Edwards and Glysson (1999), and U.S. Geological Survey (variously dated). Laboratory theory and methods of sediment analysis are described by Guy (1969). Although the latter report is used as a primary guide for the standard analytical procedures used by the USGS Montana Water Science Center Sediment Laboratory (herein referred to as the Montana Sediment Laboratory), the report does not specifically address quality assurance. Quality-assurance practices used by sediment laboratories of the USGS depend on the size of the sediment program, the objectives of the datacollection program, and the methods used by individual laboratories. Many of the quality-assurance practices commonly used by USGS sediment laboratories are described in reports by Knott and others (1992) and Lambing and Dodge (1993).

This report describes the policies and procedures used to assure the quality of results from the analysis of about 3,000 suspended-sediment samples processed annually by the Montana Sediment Laboratory in Helena, Mont. The plan documents quality-assurance policies for sediment-laboratory certification, personnel responsibilities and training, documentation requirements, and laboratory safety. The plan also documents quality-assurance procedures related to laboratory equipment and supplies, sample management, sample analysis, analytical-quality control, and data management. The procedures might be applicable to other laboratories having production capabilities similar to those of the Montana Sediment Laboratory.

\section{Quality-Assurance Policies}

Quality-assurance policies are a comprehensive set of requirements and guidelines that specify the measures used to produce data of known quality. These measures include quality-control procedures that test the performance of individual components of the laboratory operational system and are systematically applied to identify, quantify, and control errors in order to evaluate the accuracy and precision of the analytical data.

The assurance of data quality on a continuing basis is achieved by a management program that includes developing an operational design, acquiring necessary equipment and expertise to perform laboratory operations, and implementing quality-control procedures to systematically review and evaluate the analytical results. This management program is implemented by assigning responsibilities for the various components of laboratory operations to qualified personnel who have received adequate training. Data quality is verified by documenting and evaluating the results of numerous quality-control checks integrated throughout all phases of sample processing.

The USGS Montana Water Science Center (herein referred to as Center) supports quality-assurance objectives by designating discipline specialists who provide technical oversight to operations within their respective areas of expertise (Moreland, 1995). This staffing organization includes a Sediment Specialist, who is responsible for developing sediment programs and maintaining the technical adequacy of laboratory operations. Operational guidelines adapted from formal publications and internal USGS memoranda are applied in accordance with USGS policies on analysis of sediment samples. 
Within the Montana Sediment Laboratory, the qualitycontrol system contains operational checks and documentation that enable determination of the accuracy and precision of the analytical data. Quality-control procedures are implemented systematically throughout the operational sequence required to process suspended-sediment samples and report data. Quality control for equipment and procedures include actions ranging from equipment checks and simple observations to systematic, documented test results. Unacceptable errors that are identified through systematic checks are promptly evaluated for corrective action. If the corrective action requires a change in procedure, the operational guidelines are changed accordingly. Procedural changes that implement non-standard methods require approval from the USGS Office of Surface Water. Quality control, therefore, incorporates both standard guidelines and appropriate modifications to meet the objectives of maintenance and improvement of data quality.

\section{Sediment-Laboratory Certification}

In accordance with Office of Surface Water Technical Memorandum No. 91.11, "Certification Training for Sediment Laboratories," personnel responsible for the quality of laboratory results in each USGS sediment laboratory or contract laboratory must complete Water Resources Discipline (WRD) certification requirements. The policy specifies that in order for a laboratory chief to meet the first step of certification, the chief must attend WRD training to operate a sediment laboratory. This training includes an initial 1-week training period under a certified laboratory chief and attendance at periodic meetings of sediment-laboratory chiefs. Upon successful completion of this training, these employees become certified sediment-laboratory chiefs and are authorized to provide certification training in their Centers.

\section{Personnel Responsibilities and Training}

All personnel involved in sediment operations are responsible for quality assurance within the scope of their duties. The Sediment Specialist is responsible for the overall evaluation and approval of the quality of sediment data within the Center. Implementation of any procedural change requires approval by the Sediment Specialist. The Sediment Specialist is assisted by the laboratory supervisor who oversees daily laboratory operations, establishes analytical priorities, and reviews all analytical results and quality-control data generated by the laboratory. The laboratory supervisor consults with the Sediment Specialist to resolve problems identified by qualitycontrol checks. Sample management, analysis, and data entry are performed by two laboratory assistants, who also check equipment condition and document all calibration checks to verify acceptable performance.

Implementation of quality assurance begins with adequate training of laboratory personnel to develop the necessary expertise to accurately and efficiently analyze water samples for sediment. This training is provided by qualified staff with formal USGS training and experience. Laboratory manuals detailing procedures, equipment operation, and datadocumentation requirements are provided to assist laboratory analysts. New analysts are trained for each phase of sample processing and data entry until the analyst has demonstrated the ability to independently and correctly perform all procedures. The USGS Office of Surface Water also requires that each USGS sediment laboratory have at least one analyst certified through proficiency training to perform analyses to agency standards. Proficiency training is provided by the Office of Surface Water.

\section{Documentation Requirements}

All analytical quality-control measurements are documented in laboratory quality-control logbooks for each major component of sediment analysis. In addition, data that document the performance of analytical equipment are routinely entered into the logbooks. Records of equipment calibration, cleaning, and adjustments are entered in the logbooks at the time of servicing.

All quality-control records are periodically reviewed by the laboratory supervisor. These records are reviewed to identify subtle but systematic errors that might not be detected by casual observation. Persistent deviations of quality-control data from original characteristics are investigated to identify the possible source of variation. The deviations of the qualitycontrol data are brought to the attention of the Sediment Specialist and tests are designed to isolate the source of error. Evaluations of test data are used to assess the need for adjustment or servicing of equipment, or modification of analytical procedures.

The information used in the analytical processing of suspended-sediment samples is recorded on several forms. Some forms are designed to allow systematic entry of all pertinent data necessary to analyze, track, and report sample data. All final forms are stored in station files as a permanent record of data processing.

\section{Laboratory Safety}

Instructions and safety precautions for a wide range of activities that occur in the Center water-quality laboratory, of which the Montana Sediment Laboratory is a part, are generally described by Skinner and others (1983) and specifically in the USGS Montana Water Science Center Chemical Hygiene Plan (a document available in the Center). These manuals describe various laboratory procedures, hazards, safety precautions, and chemical storage requirements. All personnel who routinely or periodically work in the laboratory are required to read and sign the Chemical Hygiene Plan, which is prominently displayed in the laboratory.

Laboratory restrictions and emergency procedures are identified on signs placed on laboratory walls. An emergency 
safety shower, eyewash fountain, and acid-spill cleanup kit are located in the laboratory. Operation of the shower, eyewash fountain, and hood exhaust fans are checked periodically and inspections are documented in logbooks. Personal-safety supplies and equipment such as rubber gloves, goggles, aprons, and a chemical fume hood are provided. Two fire extinguishers, mounted on the walls (one in the center of the laboratory and the other by the safety shower), are checked annually by a certified specialist. All chemicals are stored in metal cabinets appropriate for the specific types of chemicals, clearly marked with identifying labels, and dated. A list of chemicals that are stored in the laboratory is displayed on the door of the red fireproof cabinet and is updated annually. Material Safety Data Sheets are located at the entrance to the laboratory and are readily accessible to all laboratory personnel.

\section{Quality-Assurance Procedures}

The following sections describe the specific procedures used for assuring the quality of the equipment and supplies used in the analysis of suspended sediment in the Montana Sediment Laboratory. The process and manner used to record relevant information necessary for accurate sample management, sample analysis, and data management also are described.

\section{Laboratory Equipment}

The weighing, processing, and analysis of sediment samples require a wide variety of equipment. Electronic balances, ovens, conductivity meters, vacuum pumps, and laboratory-grade thermometers are obtained from commercial sources. Specialized types of equipment, such as decanting or filtering devices, generally are assembled or fabricated to conform with processing requirements of individual laboratories. Storage shelves and processing benches also might require custom fabrication. A computer system is used for routine data entry and storage to enable efficient data management and retrieval, which is especially important for large numbers of analyses and maintenance of historical data files.

Equipment that operates properly and within specified limits of calibration is essential for producing reliable analytical results. Equipment is systematically checked to verify acceptable performance. Equipment that fails to meet accuracy standards is either calibrated or promptly serviced to achieve conformance with standards. Calibration of equipment is performed according to guidelines of the manufacturer and the USGS. Maintenance of equipment to assure proper operation is systematically performed in accordance with maintenance schedules recommended by manufacturers.

The ability of commercially available equipment to meet technical requirements of sample processing is evaluated prior to purchase. This equipment is tested and calibrated before its initial use to ensure proper performance. Manuals describing equipment operation are available for each piece of commercial equipment and serve as the operational instructions for laboratory personnel. Manufacturer representatives are consulted if problems with commercial equipment occur. Specially fabricated equipment is designed and tested for technical adequacy prior to use in sample processing.

All equipment checks, calibration, cleaning, and maintenance are documented in appropriate logbooks as part of routine quality control. Information about performance checks and calibration measurements for each electronic balance, oven, oven thermometer, and conductivity meter is recorded in a logbook. The date and analyst's initials are recorded for each log entry, followed by the performance data and comments for each item checked. The logbooks are periodically reviewed to evaluate equipment performance and to implement corrective actions, if necessary. In addition, manufacturer's operation manuals, maintenance schedules, and service forms provided by professional service representatives are stored in equipment files for each instrument. These documents are stored near each instrument for immediate access.

\section{Electronic Balances}

Two types of balances, macro and analytical, are used to determine the mass of sediment samples and containers ${ }^{1}$. The balances are electronic, provide digital readout, and have weighing capabilities that encompass the expected range of sample weights with an acceptable level of accuracy and precision. Weight is displayed in grams $(\mathrm{g})$.

The macro balance is used for items that weigh $100 \mathrm{~g}$ or more. Such items typically include empty sample bottles (tare weight) and the sample (water-sediment mixture). The macro balance used in the Montana Sediment Laboratory is capable of determining weight ranging from 0.1 to $4,000 \mathrm{~g}$, with a precision of $\pm 0.05 \mathrm{~g}$.

The analytical balance is used for items that weigh $100 \mathrm{~g}$ or less. These items typically include sediment containers (crucibles and evaporation dishes) used in laboratory analysis of sediment weight. The analytical balance used in the Montana Sediment Laboratory is capable of determining weight ranging from 0.0001 to $162 \mathrm{~g}$, with a precision of $\pm 0.0001 \mathrm{~g}$. This balance is equipped with an internal counterweight balance for automatic calibration. The analytical balance is electronically connected to the laboratory computer terminal, which enables electronic transfer and storage of balance readings. Thus, transcription errors are eliminated (fig. 1).

Both balances are located in an area of minimal vibration (restricted foot traffic) and where humidity and temperature are not subject to excessive change. The macro balance is mounted on a marble table to minimize vibrations that could affect the weight readings. The analytical balance is mounted

\footnotetext{
${ }^{1}$ To conform to traditional use, the word "weight" is subsequently used in place of the technically correct term "mass."
} 


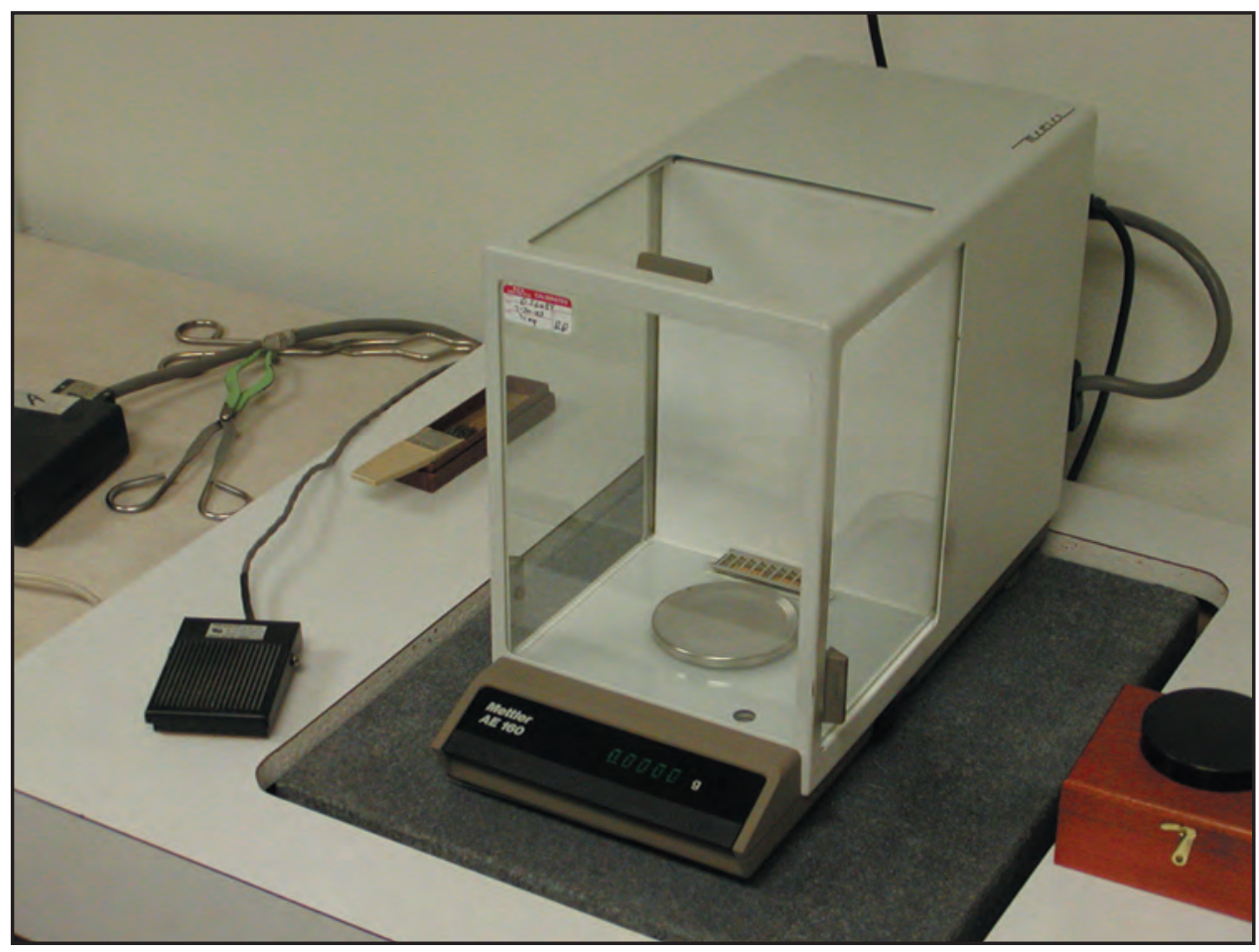

Figure 1. Analytical balance electronically connected to laboratory computer terminal.

on a sand-filled, marble-top table. This balance also has a protective hood with sliding Plexiglas panels surrounding the balance pan to provide a dust-free environment and to eliminate air currents during the weighing process (fig. 1).

The macro and analytical balances are calibrated by automatic balance controls prior to use each day. The calibration procedure is verified by weighing a series of analytical reference weights recommended by the balance manufacturer. This check provides an independent test of the internal counterweight balance used for automatic calibration. For each daily calibration check, the operator uses at least three reference weights that encompass the extremes and midpoint of the expected range of sample weights. All weight measurements for the daily calibration check are recorded in a logbook for each balance. If the results from the reference weights exceed prescribed error limits, sensitivity of the balance is adjusted as described in the manufacturer's manual. If these adjustments fail to correct the error, the balance is internally cleaned and calibrated by the manufacturer's service representative. Regardless of balance performance, both balances are cleaned annually and then calibrated with American Society for Testing and Materials Class 1 traceable weights by a service representative. The date and type of service are documented in the logbook of each balance.

During sample processing, analytical balance readings can drift slightly as a result of sensitivity to humidity and temperature changes, vibrations, or static electricity. The analyst is responsible for closely monitoring any tendency for the balance to drift from a zero $(0.0000 \mathrm{~g})$ reading when the balance pan is empty. To ensure that particulate material is not causing drift, the pan is cleaned periodically with a fine-hair brush. To minimize the effect of persistent drift, the balance is re-zeroed by a reset button on the balance-control panel after every 10 weighings, or more frequently if drift exceeds $0.0002 \mathrm{~g}$. If the balance drifts more than $0.0004 \mathrm{~g}$, a buildup of static electricity or moisture absorption from the air might be indicated. Static electricity in the typically dry environment of Montana is controlled by placement of the sediment container on a wooden platform prior to placement in the balance. A plastic platform on the balance pan also aids in minimizing static drift. Moisture absorption is minimized by weighing containers promptly after removal from desiccators. If the drift becomes excessive (greater than about $0.0005 \mathrm{~g}$ ), the balance is internally recalibrated. If the drift cannot be corrected, the balance is serviced by the manufacturer's representative.

\section{Ovens}

Two electric ovens are used to dry the sediment, the sediment containers, and various types of laboratory equipment. Both ovens are equipped with internal temperature sensors for monitoring oven performance.

The mechanical-convection oven (Oven 1) is controlled with a timer, an alarm system, and air-circulation blowers. This oven, which is used to dry water-sediment mixtures in evaporation dishes, is operated at about $93^{\circ} \mathrm{C}$. Because evaporation dishes might contain $100-250 \mathrm{~mL}$ of sample, temperatures must be maintained at less than the boiling point of water 


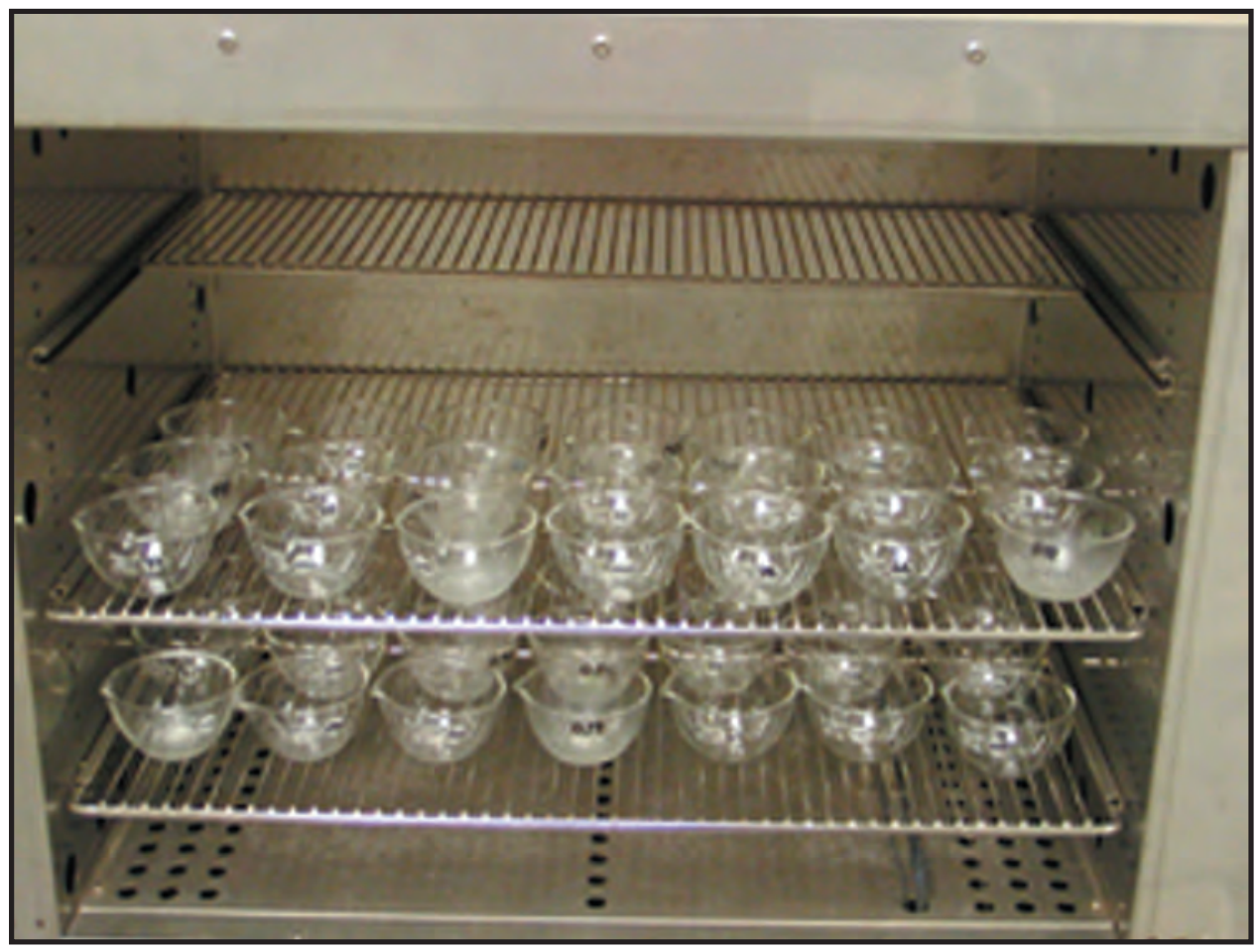

Figure 2. Mechanical-convection oven for drying sediment in evaporation dishes.

$\left(96^{\circ} \mathrm{C}\right.$ at about $4,000 \mathrm{ft}$ above sea level) to prevent splattering of samples and loss of sediment or cross-contamination of samples. The oven alarm system sounds when the temperature reaches $94^{\circ} \mathrm{C}$, thereby indicating the oven temperature is near the boiling point. The capacity of this oven is about 100 dishes (fig. 2).

The convection oven (Oven 2) is used to dry crucibles containing filters that retain the sample sediment. Because temperatures in excess of about $110^{\circ} \mathrm{C}$ can break down molecular hydration bonds of some clay minerals in the sediment, the convection oven is operated at a maximum temperature of $103^{\circ} \mathrm{C}$. The operating temperature can exceed the boiling point of water because there is no water-sediment mixture in crucibles. This oven is equipped with a simple on/off switch and is monitored by a digital thermometer mounted on the oven exterior. The capacity of this oven is about 150 crucibles (fig. 3).

Oven temperature is read twice during each day of operation and recorded in the logbook for each oven. Oven thermometers are checked twice annually at their normal operating temperature $\left(90-103^{\circ} \mathrm{C}\right)$, with results recorded in the logbook for each oven. The digital thermometer of Oven 1 is checked with a calibration thermometer of known accuracy (plus or minus $0.1^{\circ} \mathrm{C}$ ). The readings are compared and recorded. The digital thermometer on Oven 2 is checked by placing a full-immersion calibration thermometer on the center shelf. The results of these tests are recorded in the oven logbooks. The digital thermometer on Oven 1 and the internal sensor of
Oven 2 are replaced if temperature comparisons vary or cannot be adjusted by plus or minus $2.0^{\circ} \mathrm{C}$.

\section{Conductivity Meters}

A laboratory-grade conductivity meter is used to measure specific conductance of suspended-sediment samples that are processed by the evaporation (rather than filtration) method. This measurement is used to estimate the concentration of dissolved solids within the water-sediment mixture to determine the need for a dissolved-solids correction. After evaporation, the solid-phase residue contains precipitated salts. Correction for the additional weight of dissolved solids that is not part of the particulate material originally suspended in the stream is necessary for some samples. The meter also is used to verify the purity of the deionized water that is used for various water-quality activities. The conductivity meter in the Montana Sediment Laboratory is capable of measuring specific conductance ranging from 1 to $100,000 \mu \mathrm{S} / \mathrm{cm}$.

Calibration of the conductivity meter is checked each day before use with standard solutions of known specific conductance obtained from the USGS National Water Quality Laboratory. Two standards are used that bracket the expected range of specific conductance for the sample. The meter is recalibrated if more than a 3-percent difference exists between the known value of the standard solution and the displayed value of the meter. If specific conductance of the standard solution is not within an acceptable range after calibration, the sensor is cleaned and the meter is checked with another 


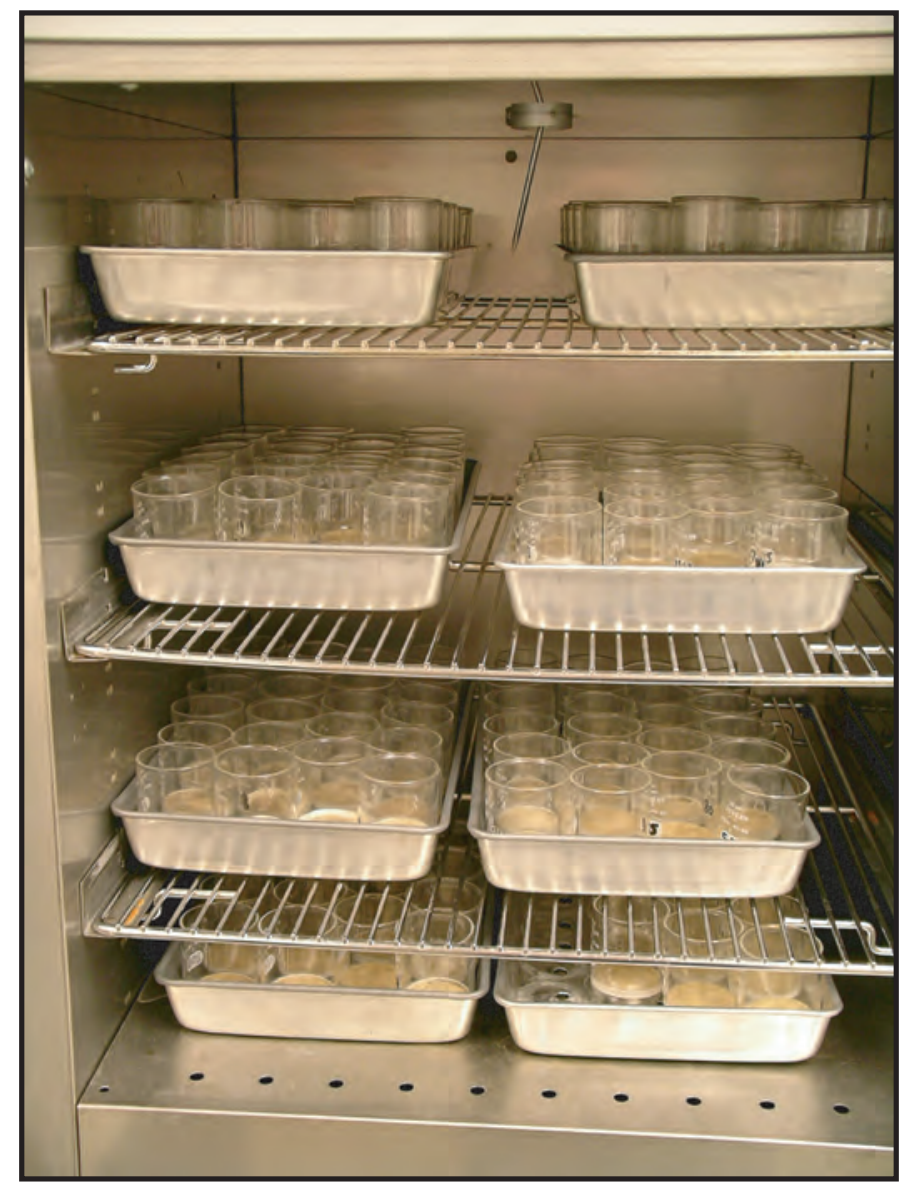

Figure 3. Convection oven for drying sediment in crucibles.

standard solution of equal or similar specific conductance to verify the exceedance of calibration limits. If the meter is in error, the sensor is replaced and the meter is retested. All the standard solutions used for calibration checks have a clearly marked expiration date that indicates freshness of the solution. Standard solutions are discarded when the prescribed expiration date is reached.

\section{Decanting Equipment}

After initial sample weights have been obtained, sample bottles have been allowed to stand undisturbed for several days and the sediment has settled to the bottom of the bottle, decanting equipment is used to remove most of the overlying sediment-free portion (supernatant) of the water-sediment mixture. The decanting equipment consists of a J-shaped nozzle made of a firm material (such as copper) inserted into flexible tubing and connected to a vacuum system. The hose system is suspended above a workbench on which the sediment samples are placed for processing (fig. 4). The decanted water moves through outflow tubing into a collection jug having a capacity of $38 \mathrm{~L}$ (10 gal). The vacuum pump used in this system is operated by a $124 \mathrm{~W}(1 / 6 \mathrm{hp})$ motor.

\section{Filtering Equipment}

Filtering equipment is used to separate the sediment from a water-sediment mixture by drawing the mixture through crucibles that have perforated bottoms and glass-fiber filters. A glass-fiber filter is placed on the bottom of the crucible to allow the passage of water while retaining the sediment. The crucibles are seated in rubber holders mounted in a fabricated crucible manifold (fig. 5). The bottom of each rubber holder is connected by a portal tube and each portal has a separate valve to control the in-line vacuum to individual crucibles. Sample water vacuumed through crucibles moves through outflow tubing into the same collection jug used for the decanted supernatant from the water-sediment mixture in sample bottles. A separate manifold is used for each of the two sizes of crucibles used in the Montana Sediment Laboratory.

\section{Laboratory Supplies}

A variety of laboratory supplies are needed to process and analyze suspended-sediment samples. Laboratory supplies that are selected must meet technical and durability performance requirements. Some of the items are disposable and purchased on a regular basis. Other items are reusable and can be cleaned and reused many times.

\section{Sample Bottles}

Standard suspended-sediment samplers used by the USGS accommodate different sizes and types of sample bottles (Edwards and Glysson, 1999). The most common types of sample bottles used in the Center are the pint glass "milk" bottle and the quart glass "mayonnaise" bottle; however, newer samplers designed for ultra-clean water-quality sampling (U.S. Geological Survey, variously dated) typically use 1-L and 3-L plastic bottles.

The sample bottles are reusable and are cleaned prior to collection of a water sample. The cleaning removes any residue that can remain after the analytical process. Sample bottles are cleaned by soaking in a water bath with a laboratory detergent, followed by a hot, tap-water rinse in an automatic dishwasher. Washed bottles are turned upside down in a wire carrying case to air dry. After drying, the bottles are turned upright and capped, and are then ready for field use. Before capping, the bottles are inspected for chips, cracks, or excessive residue. Bottles with large chips or cracks are discarded to prevent breakage in the field. Bottles with visible residue or staining that requires additional cleaning are rinsed with a 10-percent hydrochloric acid solution, using appropriate safety apparatus such as goggles and protective gloves. After acid rinsing, the bottles are rewashed and rinsed with tap water. Cleaning procedures for all types of sediment containers used in the Montana Sediment Laboratory are documented in the Chemical Hygiene Plan and are posted at the primary cleaning station. 


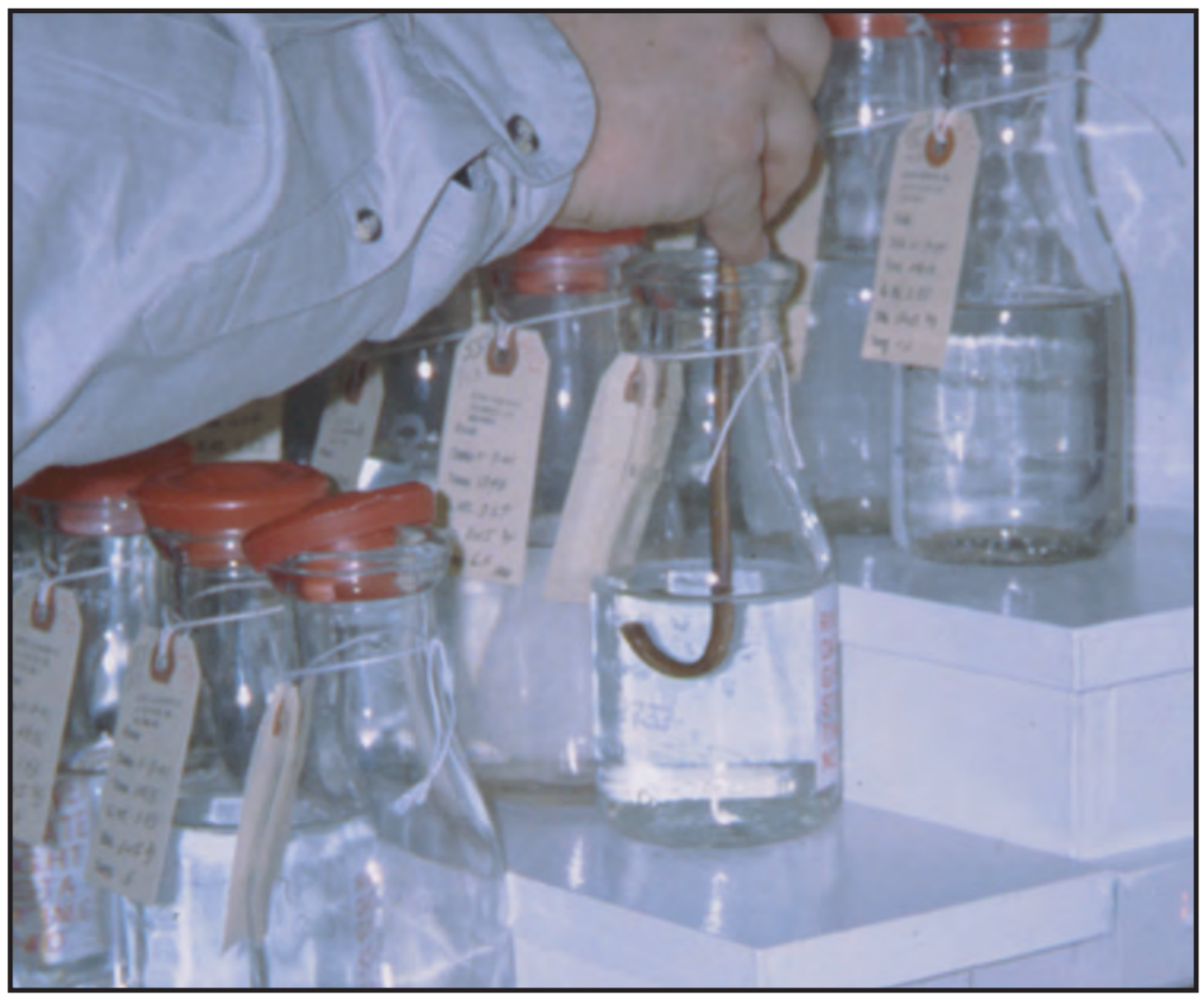

Figure 4. Vacuum-hose system and workbench for decanting water from suspended-sediment samples.

Glass sample bottles may be used for many years; therefore, bottle weights to the nearest $1 \mathrm{~g}$ (without labels, tags, or caps) are permanently etched into the surface as a record of tare weight. Plastic bottles are not as durable as glass bottles; the tare weights are recorded on the surface using a felt tip marker with permanent ink. Plastic bottles are regularly checked to verify the accuracy of the tare weight. Five percent of each batch of processed sample bottles (both glass and plastic) are randomly selected and reweighed on the macro balance after cleaning and drying. If the measured weight of any bottle differs by more than $2 \mathrm{~g}$ from the tare weight recorded on the bottle, the new tare weight is recorded on the bottle. All bottles that require extra cleaning by acid rinsing are weighed to verify the tare weight, with corrections made as necessary. If a chip is discovered on a glass bottle, the bottle is reweighed and the new tare weight is etched onto the bottle.

\section{Crucibles and Filters}

Crucibles are small porcelain or glass vessels that are resistant to heat and have a perforated base that allows the passage of water. Two sizes and types of crucibles are used by the Montana Sediment Laboratory. One type is made of porcelain with a base diameter of $2.4 \mathrm{~cm}$ and a capacity of about $25 \mathrm{~mL}$. Porcelain crucibles have an array of uniform perforations in the base. The other type is made of glass with a base diameter of $4.25 \mathrm{~cm}$ and a capacity of about $50 \mathrm{~mL}$. Glass crucibles have a base composed of an integrated frittedglass disk. All crucibles are individually numbered with hightemperature paint or indelible marker for identification.

Both types of crucibles are cleaned after completion of analysis by first removing the filter. The porcelain crucibles are soaked in a laboratory-grade detergent and then rinsed with hot tap water in the dishwasher. The glass crucibles with the fritted-glass disk in the base are soaked in warm tap water and then rinsed with hot tap water in the dishwasher. The glass crucibles are periodically cleaned using an ultrasound water bath to remove particles that can become lodged in the fritted glass. If residues are not successfully removed by ultrasound, the crucibles are soaked in a 10-percent solution of hydrochloric acid and then rewashed.

Filters are seated on the bottom of the crucible to retain sediment during sample filtration. The only filter type authorized by the USGS for suspended-sediment analysis is the Whatman glass-microfiber filter No. 934-AH or equivalent (C.W. Boning, U.S. Geological Survey, written commun., 1992). Filters are always placed in crucibles with the rough side facing the sample to prevent fiber loss during filtration.

After the crucibles have been cleaned, new filters of the correct diameter are placed in the crucibles with forceps. The filters are rinsed with about $25 \mathrm{~mL}$ of distilled water by filling the crucible with distilled water and applying vacuum 


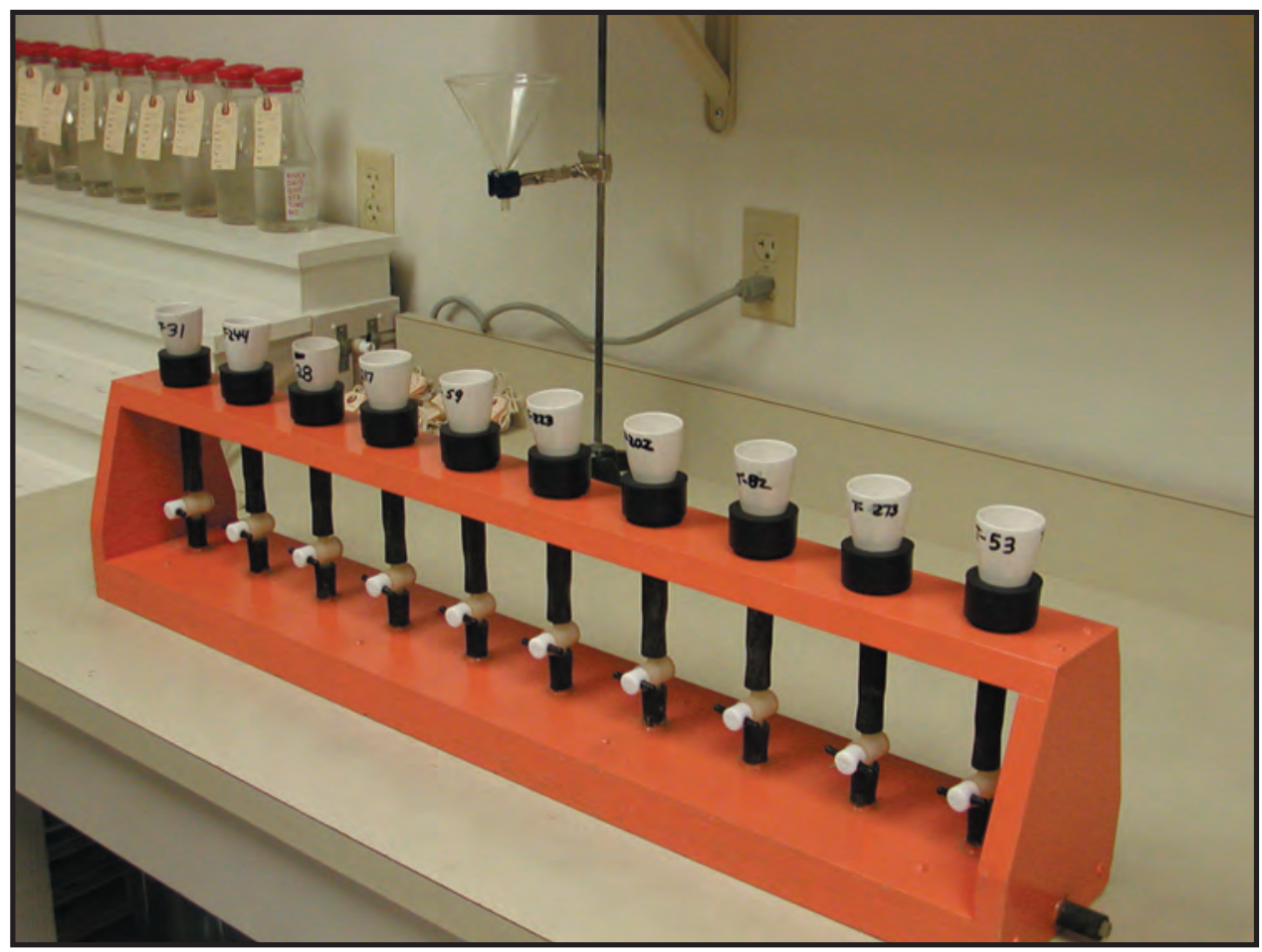

Figure 5. Manifold for vacuum filtration of suspended-sediment samples through crucibles.

pressure. The vacuum serves to seat the filters and helps remove loose fibers. The crucibles and filters are oven-dried for about 2 hours at $105^{\circ} \mathrm{C}$ to remove any moisture and allowed to cool for about 15 minutes.

After cooling, crucibles are transferred to a desiccator and remain moisture- and dust-free until needed. Because the weight of the individual filters placed in the crucibles can vary, a new tare weight for each crucible plus filter is determined for each analysis. Crucible plus filter tare weights are recorded to the nearest $0.0001 \mathrm{~g}$.

\section{Evaporation Dishes}

Evaporation dishes are small bowls made of heat-resistant glass that have a funneled lip for pouring. Evaporation dishes used in the Montana Sediment Laboratory have capacities of either 140 or $290 \mathrm{~mL}$. The dishes are individually numbered with high-temperature paint or indelible marker for identification.

Evaporation dishes are cleaned by soaking in warm tap water or soap solution, lightly brushed to remove sediment without scratching the glass, and rinsed with hot tap water in the dishwasher. The dishes are then oven-dried for 2 hours at $105^{\circ} \mathrm{C}$. After cooling for about 15 minutes, the dishes are transferred to desiccators for storage.

\section{Sieves}

Sieves are shallow metal pans with a standard-sized mesh opening that are used to separate sediment based on the size of the sediment in the sediment sample. Sediment particles with a median axis larger than the mesh openings are retained on the screen, whereas smaller sediment particles will pass through the screen. The operational definition used by the USGS to differentiate between sand and fine sediment (silt and clay) is a diameter of $0.062 \mathrm{~mm}$ (Guy, 1969). A 3-in. diameter sieve with a $0.062-\mathrm{mm}$ mesh is used by the Montana Sediment Laboratory (fig. 6) to separate sand from fine sediment.

Distilled water is used to rinse the retained sediment from the screen to a crucible or evaporation dish to ensure that all sediment from a sample has been transferred. This rinse generally constitutes adequate cleaning of the sieve before processing the next sample. The sieve is inspected for particles that can clog the screen after each sample is processed. Occasionally a few particles can become lodged in the mesh openings of the screen and cannot be removed by rinsing. When particles become lodged in the mesh openings, the sieve is gently cleaned with a nylon brush or immersed in an ultrasound bath. The screen also is inspected prior to each use to ensure that it is taut and has no tears. A sieve is replaced if the screen cannot be completely cleaned, is no longer taut, or has become torn. 


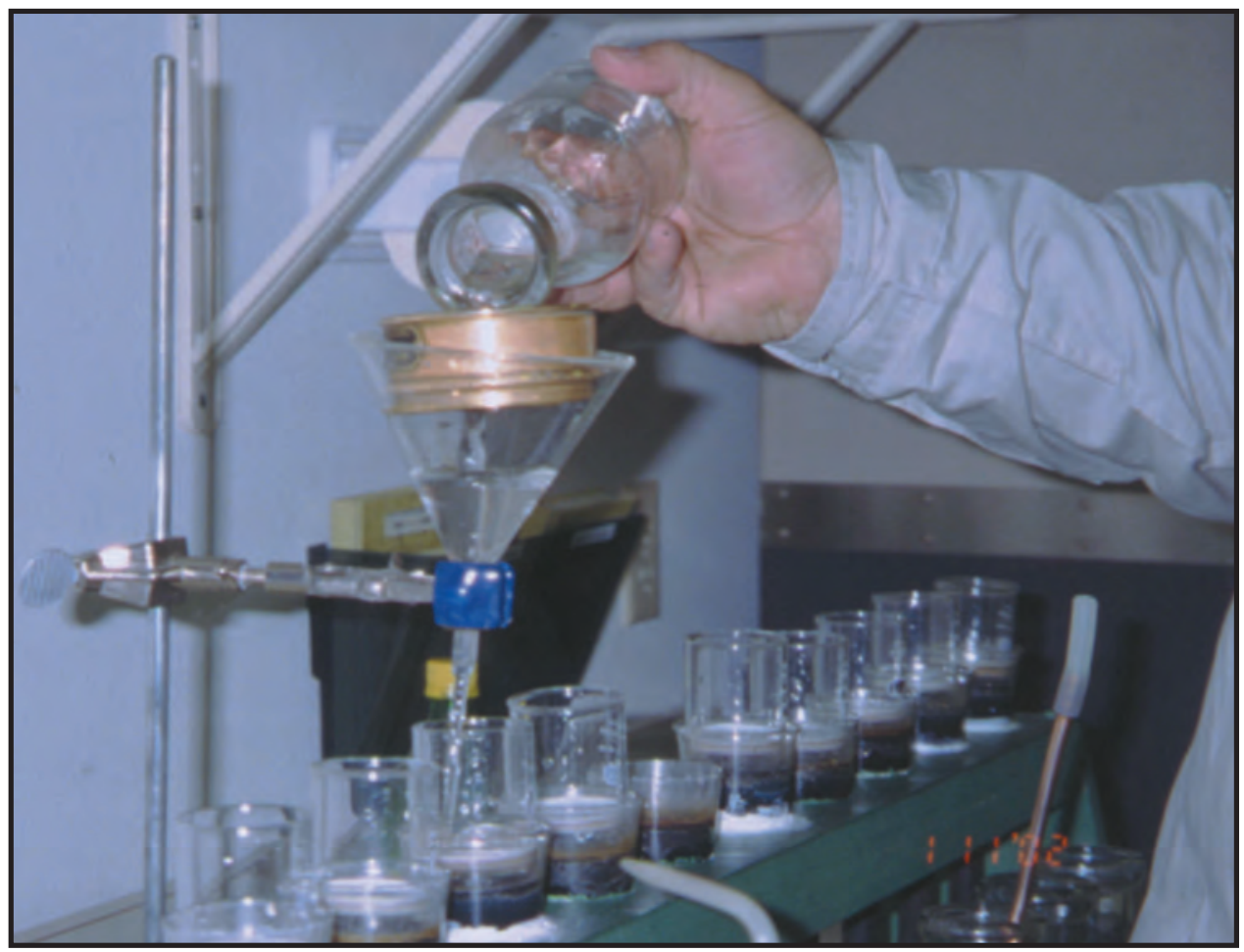

Figure 6. Suspended-sediment sample poured through a 0.062-millimeter sieve to separate sand from fine sediment.

\section{Desiccators}

To maintain a constant sample weight, crucibles and evaporation dishes are stored in desiccators after they are removed from the drying oven. Storage in desiccators prevents the absorption of moisture by filters, sediment, or container surfaces, and also prevents the deposition of airborne particles.

Moisture reduction is achieved by a desiccant placed at the bottom of the desiccator. The desiccant is granular calcium sulfate, which has a large moisture-absorption capacity. The desiccant contains a moisture indicator that changes color as moisture is absorbed; thus, desiccant color is checked before the desiccator is used. If the desiccant color has changed, the desiccant is either replaced or recycled according to manufacturer's instructions. The desiccant is recycled by baking it to restore the original color and absorption capacity.

Desiccators are inspected before use to ensure that the seal between the jar and lid is airtight. All desiccators are cleaned and regreased as needed. With the desiccant removed, a laboratory-grade detergent is used to clean the entire desiccator. New grease is applied to the jar rim and lid to maintain an airtight seal. Inspections and maintenance of all desiccators are documented in a logbook that is kept in the sediment laboratory.

\section{Distilled Water}

Distilled water is used in sediment-laboratory operations for rinsing sediment from sample bottles into crucibles and evaporation dishes, seating filters in crucibles, cleaning conductivity-meter sensors, rinsing sieves, and preparing test samples. An electric still is used in the Montana Sediment Laboratory that produces about $4 \mathrm{~L}$ of distilled water per hour from tap water. The criterion for acceptable quality of distilled water in the Center is a specific conductance of $5 \mu \mathrm{S} / \mathrm{cm}$ or less. If this criterion is exceeded, the still is disassembled and cleaned according to the manufacturer's instructions.

As part of the overall Center quality-assurance program for water-quality activities (Knapton and Nimick, 1991), distilled water is tested for specific conductance whenever the laboratory conductivity meter is calibrated. Results of these quality-assurance tests are recorded in the logbook for the conductivity meter.

\section{Sample Management}

Sample management includes the handling, treatment, and documentation required to manage sediment samples after collection and prepare them for laboratory analysis. The quality of sediment data is largely dependent on thorough 
documentation of sample identity, which is achieved by tracking the sample from the time of collection through analysis and data entry. Sample integrity is maintained by strictly adhering to established procedures for sample processing. All pertinent sample information is documented on a laboratory-number worksheet and a dish-report worksheet during sample processing to enable crosschecking of sample identity, dish assignment, and field information.

\section{Field Documentation}

The documentation for individual samples begins in the field with clear and complete recording of pertinent information on the sample-bottle tag promptly after sample collection. This information includes the station name, station number, date and time of collection, gage height, water temperature, sampling method, sampling points of a multiple-bottle set, and collector's initials. The same information is entered on a standard water-quality field form (fig. 7). Observers who are contracted to collect samples for the Center also document sample-collection information onsite using a standard sediment-sample field form (fig. 8). Supporting information regarding the sample collection and remarks on hydrologic or water-quality conditions also are reported on the field form.

\section{Shipment and Storage}

After sample collection, the tightly capped bottles are placed in secure carrying cases for shipment from the field to either a USGS office or the observer's residence. Samples typically are transported in the field vehicle used for sampling trips. During winter, samples that are transported in field vehicles are protected from freezing by vehicle heaters. For overnight storage in the field, bottles are either protected from freezing using vehicle heaters or by transferring the bottles to a heated inside location. After transport from the field, samples are stored indoors - in a cool, dark location - to prevent evaporation, freezing, or algae growth that could degrade sample integrity. Samples stored at an observer's residence are picked up by USGS personnel about every 6 weeks during routine site visits and taken to the field office for storage until samples are transported to the Montana Sediment Laboratory in Helena. Personnel of the Center office in Helena return sediment samples directly to the Montana Sediment Laboratory upon completion of a field trip; personnel from outlying field offices transport samples to the Montana Sediment Laboratory periodically on visits to the Center office.

\section{Sample Inventory}

When samples arrive at the Montana Sediment Laboratory, samples are immediately taken to a storage area for initial inventory, and receipt of all samples is documented. Sample tags are cross-checked with documentation on copies of field forms to assure that no bottles are missing and that information from both sources agree. Bottles are inspected for breakage, loose caps, spillage, or missing labels. Samples that cannot be positively identified or whose integrity is known to be degraded are removed from the processing sequence, and the conditions are noted on the field and laboratory forms. To facilitate processing, the samples are sorted according to station number and sample type and arranged in chronological order.

\section{Sample Analysis}

Sample analysis includes all the laboratory procedures used to document, prepare, and treat the samples during analytical processing. Also included are various qualitycontrol tests that indicate the accuracy and precision of the analytical results.

Two types of sample analysis are performed by the Montana Sediment Laboratory-suspended-sediment concentration and sand-fine size separation (fig. 9). Samples collected by observers from a single vertical in a stream on a daily or frequent basis typically are analyzed only for suspendedsediment concentration. Samples collected periodically by USGS personnel from multiple verticals in a stream cross section are analyzed for both suspended-sediment concentration and sand-fine size separation.

\section{Laboratory Procedures}

A variety of laboratory procedures are used to analyze suspended-sediment samples depending on the study objective, type of sample, and condition of the sample. Sediment analysis consists largely of weight determinations made at various stages in a sequence of steps that separate the sediment from the original water-sediment mixture of the sample. The primary reference of standard methodology for sedimentlaboratory operations is Guy (1969).

\section{Sample-Weight Determination}

The initial step in the analytical sequence is weighing the sample before any physical laboratory treatment. All samples are weighed within 2 weeks of receipt at the Montana Sediment Laboratory to minimize potential evaporation that would decrease the weight of the water in the water-sediment mixture.

Before samples are weighed on the macro balance, dirt or foreign material is wiped from the outside of the sample bottle. Then the sample gross weight, which includes the weight of the water-sediment mixture plus the weight of the sample bottle, is recorded. To obtain this value, the combined weight of the bottle cap and bottle tag is subtracted from the sample gross weight. An average of the combined weight of a bottle cap and tag is used as a tare correction. This step eliminates the need to remove caps and tags from each bottle before weighing. This correction is entered into the macro balance 


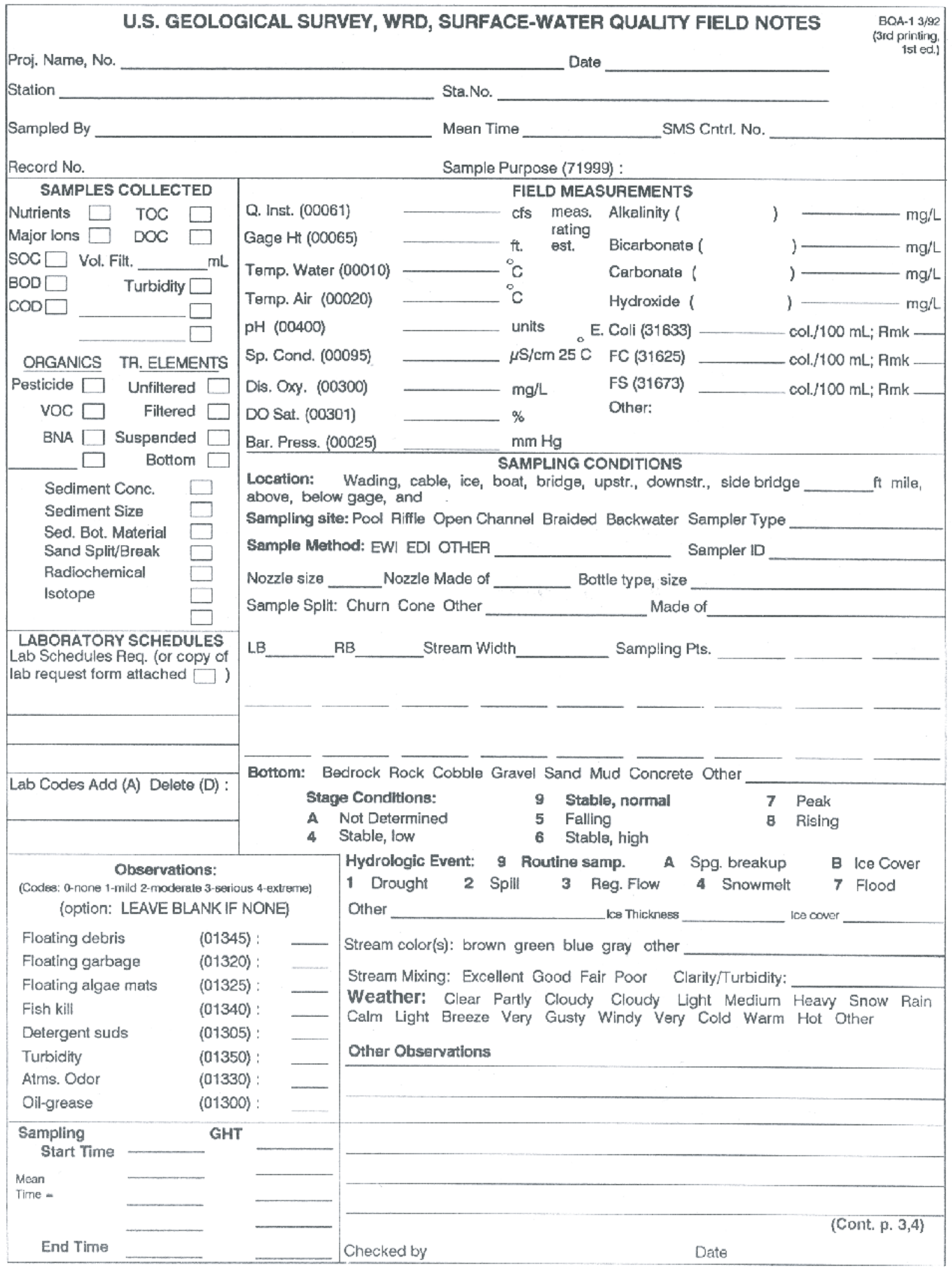

Figure 7. Example of a water-quality field form used to document information about water-quality samples collected by U.S. Geological Survey personnel. 
UNITED STATES DEPARTMENT OF THE INTERIOR

GEOLOGICAL SURVEY, MONTANA WATER SCIENCE CENTER OBSERVER SEDIMENT SAMPLE FIELD FORM

STATION

MONTH

YEAR

\begin{tabular}{|c|c|c|c|c|c|c|c|c|c|c|c|}
\hline \multirow{2}{*}{ DAY } & \multirow{2}{*}{ TIME } & \multirow{2}{*}{$\begin{array}{c}\text { GAGE } \\
\text { HEIGHT }\end{array}$} & \multirow{2}{*}{$\begin{array}{l}\text { WATER } \\
\text { TEMP } \\
\text { DEG C }\end{array}$} & \multirow{2}{*}{$\begin{array}{c}\text { NUMBER } \\
\text { OF } \\
\text { BOTTLES }\end{array}$} & \multirow{2}{*}{ TIME } & \multirow{2}{*}{$\begin{array}{c}\text { GAGE } \\
\text { HEIGHT }\end{array}$} & \multirow{2}{*}{$\begin{array}{l}\text { WATER } \\
\text { TEMP } \\
\text { DEG C }\end{array}$} & \multirow{2}{*}{$\begin{array}{c}\text { NUMBER } \\
\text { OF } \\
\text { BOTTLES }\end{array}$} & \multicolumn{2}{|c|}{$\begin{array}{l}\text { SAMP } \\
\text { LOC. }\end{array}$} & \multirow{2}{*}{ REMARKS } \\
\hline & & & & & & & & & $\mathbf{w}$ & B & \\
\hline \multicolumn{12}{|l|}{1} \\
\hline \multicolumn{12}{|l|}{2} \\
\hline \multicolumn{12}{|l|}{5} \\
\hline \multicolumn{12}{|l|}{6} \\
\hline \multicolumn{12}{|l|}{7} \\
\hline \multicolumn{12}{|l|}{11} \\
\hline \multicolumn{12}{|l|}{12} \\
\hline \multicolumn{12}{|l|}{13} \\
\hline \multicolumn{12}{|l|}{14} \\
\hline \multicolumn{12}{|l|}{15} \\
\hline \multicolumn{12}{|l|}{16} \\
\hline 17 & & & & & & & & & & & \\
\hline 18 & & & & & & & & & & & \\
\hline 24 & & & & & & & & & & & \\
\hline 25 & & & & & & & & & & & \\
\hline 26 & & & & & & & & & & & \\
\hline 27 & & & & & & & & & & & \\
\hline 28 & & & & & & & & & & & \\
\hline 29 & & & & & & & & & & & \\
\hline 30 & & & & & & & & & & & \\
\hline 31 & & & & & & & & & & & \\
\hline
\end{tabular}

Use the first four columns after the day, unless you are requested to sample more than once daily. OBSERVER'S SIGNATURE

Figure 8. Example of a sediment-sample field form used to document information about suspended-sediment samples collected by observers. 


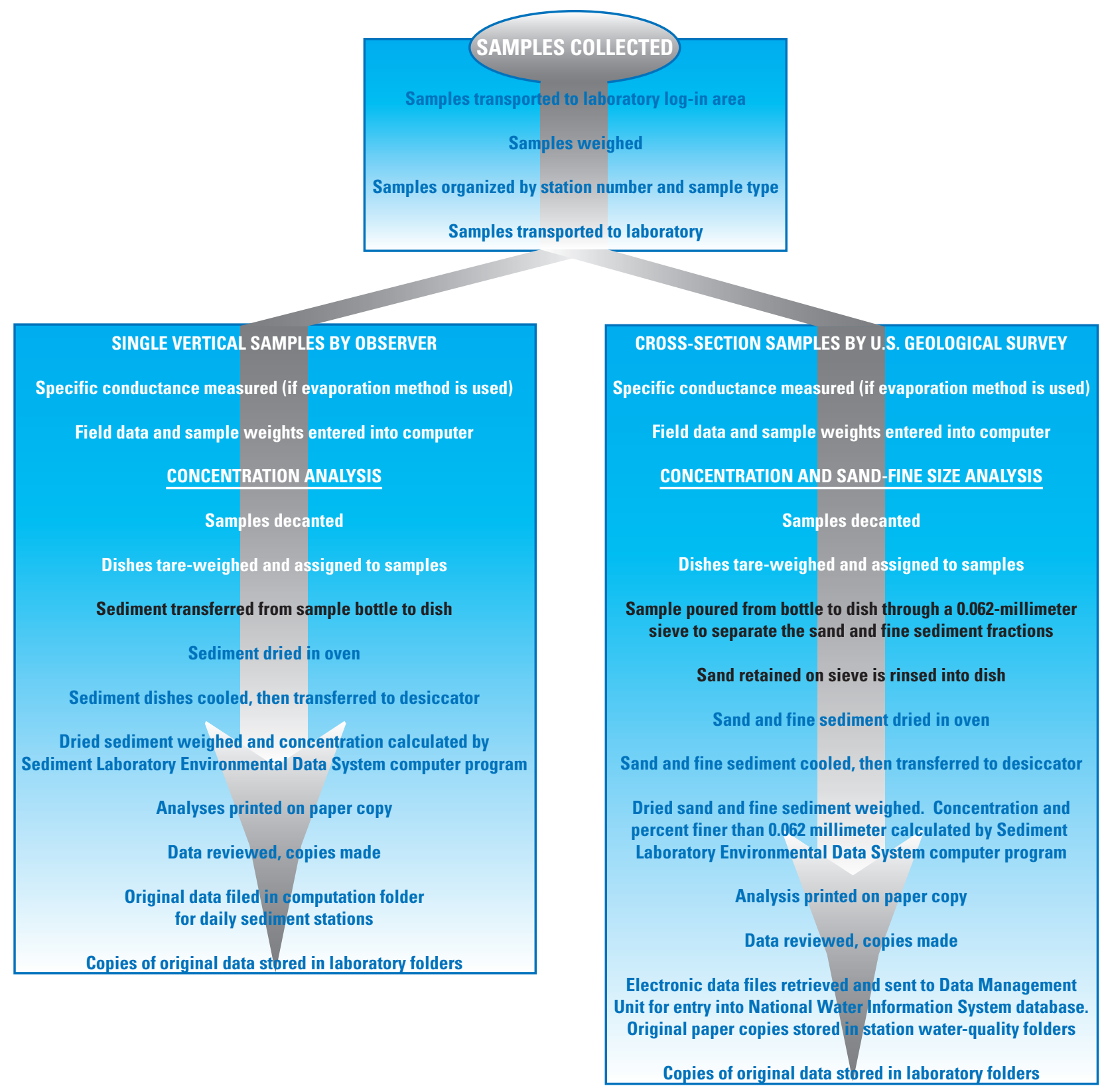

Figure 9. Operational sequence for the analysis of suspended-sediment samples in the Montana Sediment Laboratory. 
and is subsequently subtracted from the sample gross weight. The sample gross weight is recorded in bold notation on the bottle tag.

\section{Sample Preparation}

After the sample gross weight is determined for each bottle, the samples are brought from the storage area to the laboratory for processing preparation. At this step, the samples are inspected for sediment quantity to determine whether filtration or evaporation is required. The determination is based on the depth of sediment in the bottom of the sample bottle and the likelihood of clogging a filter. If the analyst decides that the sample is to be processed by evaporation, specific conductance is measured and a known volume of water is decanted from the surface of the sample to determine a dissolved-solids correction.

Sample data are entered in stages that correspond to the physical processing of the samples. Sediment Laboratory Environmental Data System (SLEDS), a computer program developed by the Cascades Volcano Observatory (CVO) of the USGS (U.S. Geological Survey, SLEDS training manual, no date), is used to enter, compute, and store sample information and analytical results for samples collected by observers and USGS personnel. Documentation of the SLEDS training manual is available in the Montana Sediment Laboratory, or from CVO in Vancouver, Wash.

The SLEDS program is formatted into three menus: (1) LOGIN menu, which includes entry of field data, requested analyses, and bottle weights (gross and tare); (2) ANALYSES menu, which includes assignment of dishes to samples, entry of dish tare weights, and entry of dish gross weight after sediment is dried; and (3) REPORTS menu, which generates output summary reports and electronic data files for computer data entry.

After the appropriate method of analysis is selected (filtration or evaporation), information for individual sample bottles is initially entered in the LOGIN menu. The initial data entry includes station number, project number, medium code, sample type, hydrologic condition, collector's initials, sample collection date, collection time, gage height, sampling station (cross-section location), water temperature, specific conductance (if required), sample gross weight, and bottle tare weight.

The next step in sample preparation is to enter data in the ANALYSES menu. This menu allows the user to enter data into four subroutines: Tare weights, Dish report, Dish assignment, and Gross weights. In the Tare weights subroutine, a file is created that assigns crucibles and evaporation dishes to sediment samples. Dishes are identified by dish type (crucibles or evaporation dishes), a unique dish number, and the tare weight (the tare weight for crucibles is determined with clean filters in place). After the tare weights have been determined, the containers are either used immediately or stored in desiccators until needed. All containers are handled with tongs to prevent moisture or finger oils from adhering to the container surface.

The next step in sample preparation is arranging the sample bottles on the processing bench by station number and in chronological order. As the bottles are arranged, dishes are assigned to each sample in the Dish assignment subroutine of SLEDS. This subroutine allows the user to choose the number of dishes and the type of material (composite, sands, or fines) that will be added to each dish. The Dish report subroutine is normally used to create a report that documents which dishes are assigned to which samples. This subroutine also is used when bottle tare weights need to be determined after the sediment sample is removed. This report allows the analyst to accurately match the sample bottle with the assigned dishes.

The samples are allowed to sit for a minimum of 24 hours, which allows all sediment to settle to the bottom of the bottle. After complete settling, most of the overlying water is decanted. The overlying water can be removed because all the sediment is retained at the bottom of the bottle and the original weight of the sample (sample gross weight) has previously been determined and recorded. A J-shaped tube connected to a vacuum hose is inserted into each bottle and held carefully at the water surface. As the water is suctioned off (fig. 4) and the water level begins to drop, the J-tube is slowly lowered while decanting the overlying water. The water is decanted at a withdrawal rate of about $1.0 \mathrm{~L} / \mathrm{min}$ $(0.3 \mathrm{gal} / \mathrm{min})$ under a vacuum pressure of $0.5 \mathrm{~kg} / \mathrm{cm}^{2}(15 \mathrm{in}$. mercury). The decanted water is drained into a collection jug for subsequent disposal. Vacuum withdrawal proceeds until the water is decanted to about $25 \mathrm{~mm}(1 \mathrm{in}$.) above the bottom of the bottle. Because the entry port of the J-tube is above the bottom of the tube and slow withdrawal of the overlying water prevents turbulence, all of the original sediment and about $30 \mathrm{~mL}$ of sample is retained in the bottle after decanting. Final separation of sediment from the remaining water-sediment mixture is achieved by filtration or evaporation.

\section{Filtration Method}

The filtration method is used to analyze samples having a suspended-sediment concentration of less than about $300 \mathrm{mg} / \mathrm{L}$. The advantage of this method is that water passes through the Whatman glass-microfiber filter but sediment is retained; thus, any dissolved solids present in the water also are removed. As a result, drying and weighing of the sediment can proceed directly without any correction for the weight of dissolved solids. The disadvantage of the filtration method is that a large quantity of sediment, especially fine sediment, can quickly clog the filter and prevent the passage of water. The size of the crucible to be used is determined on the basis of the amount of sediment in the bottle. Prior to filtration, a Dish report containing the crucible assignment for the sample is retrieved and a final crosscheck between the crucible and the sample bottle is made to verify a correct match. 
The crucibles are firmly seated in rubber holders on the manifold (fig. 5) and the vacuum pump is started. Each crucible is rinsed with distilled water to wet the filter to ensure a good seating and facilitate uniform sample dispersal. The vacuum line to the first crucible of the sequence is then opened by an in-line valve. A glass funnel attached to a movable ring-stand (figs. 5 and 6) is positioned over the first crucible. The sample is vigorously stirred with a rubber-tipped stirring rod and the stirring rod is rinsed with distilled water while in the bottle to remove any sediment; the rod is then placed in the next bottle in the sequence. The contents of the bottle are slowly poured into the glass funnel to drain into the first crucible that is under a vacuum. To prevent overfilling of the crucible, the sample is poured at a rate that does not exceed the filtration rate. As the sample is filtered through the crucible, the bottle and glass funnel are rinsed thoroughly with distilled water to flush all the remaining sediment into the crucible. When rinsing is complete, the vacuum line to the first crucible is closed and the line to the second crucible is opened. The same procedure is repeated for each bottle and crucible in the manifold.

After the entire manifold of crucibles has been processed, the crucibles are placed in chronological sequence in a drying tray. Rubber tips on fingers are used for secure and clean handling during the transfer. The next set of crucibles is inserted into the manifold, verified for cross-match, and the above procedures repeated. When the drying tray is full, the tray of crucibles is placed in the convection oven for 3-4 hours at $100-103^{\circ} \mathrm{C}$.

After oven drying, the crucibles are allowed to cool for about 15 minutes. Hot crucibles are not placed into desiccators because air expansion caused by heating could force the lid off the desiccator. The warm crucibles are placed in desiccators for a minimum of 4 hours before final weighing to allow final cooling and prevent moisture accumulation from ambient humidity. The crucibles are stacked in reverse chronological order from the bottom of the desiccator to allow subsequent removal from the top in chronological order to facilitate data entry. Warm crucibles must not be placed in the analytical balance because the heat will cause erratic readings.

\section{Evaporation Method}

The evaporation method is used to analyze samples having a large quantity of fine sediment that cannot be easily filtered (generally more than $300 \mathrm{mg} / \mathrm{L}$ ). The evaporation method requires that the initial concentration be adjusted for the weight of dissolved solids that precipitate as a solid residue as the water evaporates. The dissolved-solids concentration and the volume of the sample after decanting $(30 \mathrm{~mL})$ is needed to calculate the weight of the dissolved solids present in the decanted sample.

The method used by the Montana Sediment Laboratory is to measure the dissolved-solids concentration in an aliquot of supernatant (the clear, overlying water in the sample bottle) withdrawn from each sample. Aliquots of known volume are evaporated in the oven in dishes and subsequently weighed to determine the net weight of the dissolved-solids residue. The dissolved-solids correction for evaporated sediment samples is determined using the equation:

$$
D S C=[A B / C] D
$$

where

$D S C \quad$ is the dissolved-solids correction, in grams;
$A \quad$ is the volume of water-sediment mixture in
each bottle after decanting, in milliliters;
$B \quad$ is the net weight of dissolved-solids residue in
evaporation dish, in grams;
is the volume of supernatant aliquot, in
milliliters; and

The DSC is then subtracted from the total-sediment weight for the sample set to determine a final concentration. If a sand-fine size separation is determined for samples analyzed by the evaporation method, the $D S C$ is subtracted from the net weight of the fine fraction because the fine fraction is the portion of the sample that passed through the sieve and retains the stream water from the original water-sediment mixture in the sample bottle (the sand fraction only retains distilled water from the sieve rinse).

Similar to the filtration method, the sample bottles and corresponding evaporation dishes are arranged in sequence on a processing bench. A Dish report is retrieved and used to crosscheck and verify the correct match of bottle to dish.

The evaporation dishes are placed in the mechanical oven at $92-94^{\circ} \mathrm{C}$ until standing water has evaporated (up to 24 hours for samples with large quantities of fine sediment). After the standing water has been evaporated from the dish, the samples are dried for an additional hour at $103^{\circ} \mathrm{C}$ (to remove any residual moisture adhering to sediment particles) and then allowed to cool for about 15 minutes in the oven. When no longer hot, the dishes are transferred to desiccators for a minimum storage time of 4 hours for additional cooling and drying before they are weighed.

\section{Composited Samples}

The average concentration of suspended sediment in the cross section of a stream is determined by collecting a depthintegrated sample at multiple verticals across the stream using procedures described by Edwards and Glysson (1999). The procedures provide a volume of sample from each vertical that is proportional to the flow (discharge-weighted), thereby allowing individual bottles from multiple verticals to be composited and analyzed collectively. 
Each bottle of a multi-bottle cross-sectional sample may be analyzed individually for concentration if the equaldischarge increment (EDI) sampling method was used (Edwards and Glysson, 1999, p. 51). Concentration analysis of each bottle indicates the cross-sectional variation in concentration across the stream. Bottles of a cross-sectional sample set obtained by other sampling methods are not analyzed individually, but rather are physically composited to determine total sample and total-sediment weights for all the bottles combined. If the samples are collected by the EDI method, the volume of sample in each bottle needs to be equal or nearly equal to be composited (Edwards and Glysson, 1999, p. 49.) The average cross-sectional concentration for composited samples is calculated from the ratio of total-sediment weight to total-sample weight.

Visual inspection of sediment quantity is used as a guide to determine the number of crucibles or evaporation dishes needed to composite multi-bottle sample sets. For samples having very small sediment quantities, the contents from several or all bottles of a cross-sectional sample set can be filtered through one or two crucibles without substantial clogging of the filter. Samples having a larger quantity of sediment or predominance of fine material might require a separate crucible or evaporation dish for each bottle. Samples having very large sediment quantities that are processed only by the evaporation method might require splitting the contents of a single bottle into two or more dishes to accommodate the extra rinse water needed to extract the sediment. Regardless of the number of containers used to composite bottles of a cross-sectional sample, the dish-identification numbers and tare weights are clearly recorded along with the corresponding sample-identification information for each sample bottle processed. Thorough documentation of the compositing process enables tracking of the sample treatment, accurate calculation of concentration, and the assignment of analytical results to the correct sample.

\section{Particle-Size Analysis}

The distribution of particle size is determined by the proportion of sediment weight in each of two sediment-size classes relative to the total-sediment weight. The particle-size analysis conducted by the Montana Sediment Laboratory is the sand-fine separation, which determines the weight of suspended sediment in two size classes - the coarse fraction having particle diameters equal to or greater than $0.062 \mathrm{~mm}$ (sand size and larger), and the fine fraction having particle diameters less than $0.062 \mathrm{~mm}$ (silt size and smaller). The particle diameter of $0.062 \mathrm{~mm}$ represents the transition between the two fractions (Guy, 1969) and is, by convention, termed "sand-fine break" (also referred to as sand-silt break, as $0.062 \mathrm{~mm}$ represents the break in the size scale between very fine sand and coarse silt). A particle-size analysis typically is performed only on cross-sectional samples, although the analysis also is performed on some single-vertical samples with unusually large concentrations.
Similar to the concentration analysis, containers are assigned to the sample set and their identification numbers and tare weights are recorded. The containers are further identified on the Dish report as to whether they will receive the sand (equal to or greater than $0.062 \mathrm{~mm}$ ) or fine (less than $0.062 \mathrm{~mm}$ ) fraction. Judgment by experienced laboratory personnel is required to ensure that enough containers are assigned for each fraction. The Dish report also is used to crosscheck and verify the correct match of the bottle to container.

To determine the proportion of sediment in each of the two size classes, the sediment is physically separated by pouring the decanted sample through a 3 -in. diameter sieve having mesh openings of $0.062 \mathrm{~mm}$ (fig. 6). The first sample bottle of the sample set is slowly poured through the sieve and drained through the glass funnel into the first container assigned to the fine fraction. The sample bottle is thoroughly rinsed, with all rinse water also drained through the sieve into the same container. The sieve retains all sediment particles greater than $0.062-\mathrm{mm}$ diameter. The glass funnel with the sieve is subsequently moved to the next container assigned to the fine fraction and the next bottle of the sample set is poured. The process is repeated until all sample bottles of the set have been poured and rinsed through the sieve and into the fine-fraction containers. The sediment on the screen accumulated from all the bottles is gently rinsed with distilled water over the last fine-fraction container to ensure that all material finer than $0.062 \mathrm{~mm}$ is flushed off of the sand and through the screen. At this point, all coarse sediment (sand fraction) from the entire sample set resides on top of the sieve screen. The sieve is lifted out of the funnel and the interior surface of the funnel is thoroughly rinsed with distilled water into the last fine-fraction container to remove any residual fine sediment.

The final step in the separation is to transfer the coarse sediment from the sieve to the container assigned to the sand fraction. This transfer is accomplished by moving the glass funnel over the coarse-fraction container. The sieve is inverted into the glass funnel so that the coarse sediment is now on the underside of the screen. The coarse sediment is backflushed into the coarse-fraction container by thoroughly rinsing the sieve and funnel with distilled water. All containers for the sample set are then transferred to the oven for drying.

In addition to the two size fractions, other size classes can be determined. Complete particle-size distribution typically is analyzed only for samples having large suspended-sediment concentrations or for special studies because the analytical procedures generally require a substantial quantity of sediment ( $1 \mathrm{~g}$ or more). Complete particle-size distribution is not determined in the Montana Sediment Laboratory, but rather the samples are sent to the USGS Iowa Sediment Laboratory in Iowa City, Iowa, which routinely analyses sediment for more than two size classes. Quality assurance for complete particle-size analysis is implemented according to policies and procedures of the Iowa Sediment Laboratory, as described by Matthes and others (1992). 
Samples determined to have a quantity of sediment that is sufficient for a complete size analysis are weighed and then decanted and transferred to small shipping bottles. The original bottle tag containing the field information is attached to the shipping bottle. The sample net weight (sample gross weight minus bottle tare weight) is recorded on the tag and labeled "sample net weight." All field information and sample weights for samples shipped to the Iowa Sediment Laboratory are manually recorded on a laboratory-analysis form, which is kept in files at the Montana Sediment Laboratory. The samples are then shipped in a special padded carton, and a form from the Iowa Sediment Laboratory that contains sample-collection and analytical request information (fig. 10) is included. The original form is filed at the Montana Sediment Laboratory and a copy is shipped with the samples.

\section{Sediment-Weight Determination}

After the sediment has been oven-dried, the containers are removed from the ovens, cooled, and transferred to desiccators for storage until final weighing. Weighing can begin when the containers have been desiccated for at least 4 hours.

The containers are sequentially placed on the balance pan to maintain chronological order for daily samples ${ }^{2}$. Balance doors are always closed before recording a weight. After a container is placed on the pan and the container and balance are stable, the weight is recorded. The weight of the container plus dry sediment (and dissolved-solids residue for evaporated samples) is recorded as the sediment gross weight. After this weight is recorded, the dish is removed and placed in a holding tray. Dishes are not washed for reuse until the analytical results have been reviewed and accepted as satisfactory by the laboratory supervisor. Reweighing may be needed to verify questionable results.

The sediment tare weight (dish weight) and weight of the dissolved-solids residue, if applicable, are subtracted from the sediment gross weight to obtain the sediment net weight, which is the weight of the dry sediment. Gross weights is the last subroutine of SLEDS in the ANALYSES menu and is used for entering the weight of the dry sediment. These subtractions are done automatically by the SLEDS program.

\section{Calculation of Results}

After the weight of dry sediment has been determined, the suspended-sediment concentration can be calculated. The analytical procedures for determining suspended-sediment concentration use the measurement of weight rather than volume, so the reported concentrations actually represent a ratio of sediment weight to sample weight ratio or parts per million (ppm.) This unit of measure is essentially equivalent to

\footnotetext{
${ }^{2}$ Even though the Montana Sediment Laboratory organizes dishes sequentially, final weights can be entered in any order because a specific dish is assigned to a specific sample in the Dish assignment subroutine of SLEDS.
}

the ratio of weight to volume or milligrams per liter $(\mathrm{mg} / \mathrm{L})$ at concentrations less than about $8,000 \mathrm{ppm}$. At concentrations of $8,000 \mathrm{ppm}$ or greater, a correction for change in specific weight is applied in accordance with conversion factors listed in table 1. This correction converts concentration values in parts per million to milligrams per liter. Suspended-sediment concentration is calculated according to the equation:

$$
C=(A / B)(1,000,000)
$$

where

$$
\begin{aligned}
& C \quad \text { is the suspended-sediment concentration, in } \\
& \text { parts per million; } \\
& A \quad \text { is the net weight of dry sediment, in grams; } \\
& \text { and } \\
& B \quad \text { is the net weight of sample, in grams. }
\end{aligned}
$$

The concentration is automatically calculated by the SLEDS program. Significant figures reported for concentration are 1 for $1-9 \mathrm{mg} / \mathrm{L}, 2$ for $10-99 \mathrm{mg} / \mathrm{L}$, and 3 for concentrations equal to or greater than $100 \mathrm{mg} / \mathrm{L}$.

The results of particle-size analyses are reported as percent of total-sediment weight finer than an indicated particle diameter. The sand-fine separation analysis by the Montana Sediment Laboratory is reported as percent of suspended sediment finer than $0.062 \mathrm{~mm}$. Other size classes analyzed by the Iowa Sediment Laboratory are reported in the same manner for each particle-size analysis.

The percent of sediment finer than $0.062 \mathrm{~mm}$ is calculated by adding the sediment net weight from all bottles of a sample set to determine a total-sediment net weight. The weight of the fine fraction is determined by adding the individual sediment net weights for each of the fine-fraction containers. The combined-sediment net weight of the fine fraction (minus the dissolved-solids correction, if applicable) is then divided by the total-sediment net weight of the sample set and multiplied by 100 to obtain the percent of sediment finer than $0.062 \mathrm{~mm}$.

\section{Analytical Quality Control}

Analytical quality control is used to maintain and verify the adequate performance of analytical procedures in order to produce data of known quality. Implementation of analytical quality control includes internal testing of quality-control samples and external testing by the Sediment Laboratory Quality Assurance (SLQA) Program and formal USGS laboratory reviews. Records of analytical quality control are systematically reviewed to identify sources of error.

\section{Internal Testing}

Internal testing of the analytical process includes recording all analytical results for the following quality-control samples: evaporation blanks, sample blanks, filter blanks, 


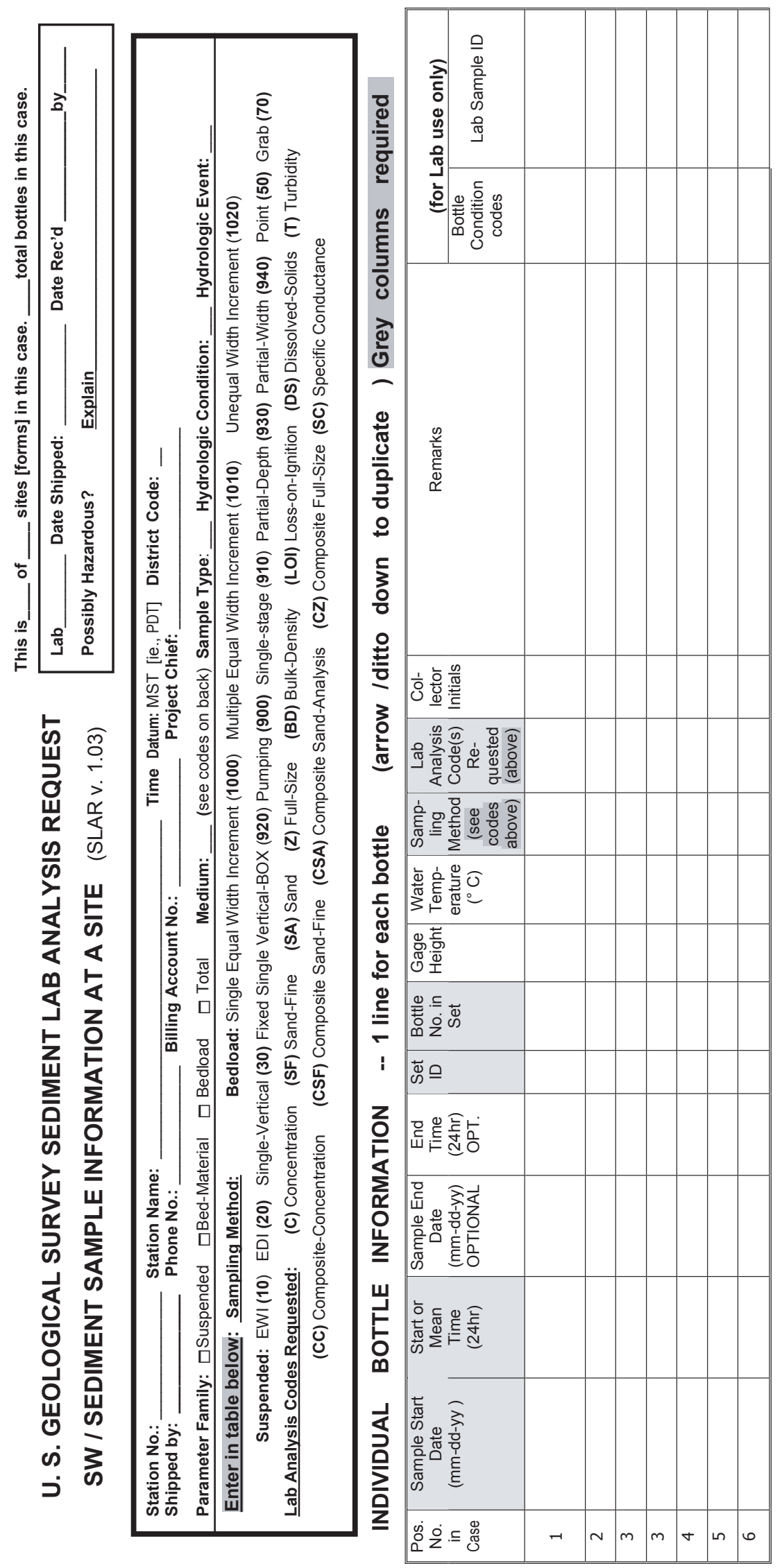

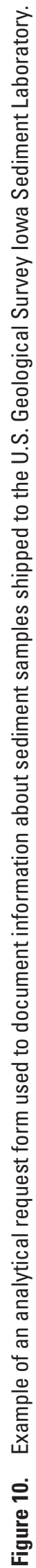


Table 1. Factors for converting suspended-sediment concentration from parts per million to milligrams per liter ${ }^{1}$.

[Conversion factors are based on the assumption that the density of water is $1.000 \mathrm{~g} / \mathrm{cm}^{3}$ plus or minus $0.005 \mathrm{~g} / \mathrm{cm}^{3}$, the range of temperature is $0-29$ degrees Celsius, the specific gravity of sediment is 2.65 , and the dissolved-solids concentration is less than $10,000 \mathrm{ppm}$. Abbreviations: $\mathrm{g} / \mathrm{cm}^{3}$, grams per cubic centimeter; ppm, parts per million]

\begin{tabular}{|c|c|c|c|}
\hline $\begin{array}{c}\text { Suspended-sediment } \\
\text { concentration range } \\
\text { (ppm) }\end{array}$ & Conversion factor & $\begin{array}{c}\text { Suspended-sediment } \\
\text { concentration range } \\
\text { (ppm) }\end{array}$ & Conversion factor \\
\hline $0-7,990$ & 1.00 & $327,000-336,000$ & 1.26 \\
\hline $8,000-23,700$ & 1.01 & $337,000-346,000$ & 1.27 \\
\hline $23,800-39,200$ & 1.02 & $347,000-356,000$ & 1.28 \\
\hline $39,300-54,300$ & 1.03 & $357,000-366,000$ & 1.29 \\
\hline $54,400-69,200$ & 1.04 & $367,000-375,000$ & 1.30 \\
\hline $69,300-83,700$ & 1.05 & $376,000-385,000$ & 1.31 \\
\hline $83,800-98,000$ & 1.06 & $386,000-394,000$ & 1.32 \\
\hline $98,100-112,000$ & 1.07 & $395,000-403,000$ & 1.33 \\
\hline $113,000-126,000$ & 1.08 & $404,000-412,000$ & 1.34 \\
\hline $127,000-139,000$ & 1.09 & $413,000-421,000$ & 1.35 \\
\hline $140,000-153,000$ & 1.10 & $422,000-429,000$ & 1.36 \\
\hline $154,000-166,000$ & 1.11 & $430,000-438,000$ & 1.37 \\
\hline $167,000-178,000$ & 1.12 & $439,000-446,000$ & 1.38 \\
\hline $179,000-191,000$ & 1.13 & $447,000-455,000$ & 1.39 \\
\hline $192,000-203,000$ & 1.14 & $456,000-463,000$ & 1.40 \\
\hline $204,000-215,000$ & 1.15 & $464,000-471,000$ & 1.41 \\
\hline $216,000-227,000$ & 1.16 & $472,000-479,000$ & 1.42 \\
\hline $228,000-251,000$ & 1.17 & $480,000-487,000$ & 1.43 \\
\hline $240,000-251,000$ & 1.18 & $488,000-495,000$ & 1.44 \\
\hline $252,000-262,000$ & 1.19 & $496,000-502,000$ & 1.45 \\
\hline $263,000-273,000$ & 1.20 & $503,000-510,000$ & 1.46 \\
\hline $274,000-284,000$ & 1.21 & $511,000-517,000$ & 1.47 \\
\hline $285,000-295,000$ & 1.22 & $518,000-525,000$ & 1.48 \\
\hline $296,000-306,000$ & 1.23 & $526,000-532,000$ & 1.49 \\
\hline $307,000-316,000$ & 1.24 & $533,000-539,000$ & 1.50 \\
\hline $317,000-326,000$ & 1.25 & & \\
\hline
\end{tabular}

${ }^{1}$ W.H. Durum, U.S. Geological Survey, written commun., 1972. 
field replicates, method-comparison replicates, and extracted sample water. These internal tests are used to verify that procedures were properly implemented during sample analysis and provide evidence of the presence and magnitude of consistent bias resulting from systematic procedural errors. The type and magnitude of error provide guidance in modifying procedures to correct the error. Inconsistent variability resulting from random procedural error is less easily identified and controlled. These errors are controlled in a general manner by adequate training and supervision of laboratory analysts and by a prompt review of analytical results by the laboratory supervisor. Results of all analyses of quality-control samples are recorded in a quality-control logbook and periodically reviewed by the laboratory supervisor.

\section{Evaporation Blanks}

Evaporation blanks are used to document the volume of sample potentially lost to evaporation during extended field storage. Analytical results can be affected if an excessive quantity of water evaporates during storage, decreasing the original sample volume. Evaporation of water from the sample decreases the sample net weight, which could result in an increase in concentration. Sample evaporation is most likely to occur in observer-collected daily samples that are stored at an observer's residence for an extended period. Evaporation is minimized by using tight-fitting bottle caps, keeping bottles in a dark, cool location during storage, and promptly weighing samples within 2 weeks after arrival at the Montana Sediment Laboratory.

Evaporation blanks consist of a tightly capped sample bottle containing $300 \mathrm{~mL}$ of distilled water. The sample gross weight is determined, and one blank per 120 bottles is placed in the cases of empty sample bottles supplied to the observer during site visits. Therefore, the evaporation blank is exposed to the same ambient temperature, sunlight, and humidity as the suspended-sediment samples collected and stored by observers. After the samples are retrieved from the observer's residence and brought to the laboratory, the evaporation blanks are reweighed to determine the magnitude of any weight loss. The weight of water evaporated can then be used to evaluate the effect on concentrations and determine if adjustments need to be made to the sample net weights measured in the laboratory. All evaporation data are recorded in a quality-control logbook and reviewed by the laboratory supervisor.

\section{Sample Blanks}

Samples of distilled water are analyzed with routine suspended-sediment samples to document the probable magnitude of systematic processing and weighing errors. Weight might be gained from the transfer of sediment between bottles owing to incomplete rinsing of the decanting J-tube, stirring rod, or funnel. Weight gains also might result from incomplete oven drying or subsequent moisture absorption after containers are removed from the oven. Weight loss might result if filter fibers are detached during filtration.
Two distilled-water sample blanks are analyzed for every bench of samples (120 bottles). One blank (300 mL of distilled water) is placed at the beginning of the analytical sequence as an initial reference and one is placed at the end to optimize detection of possible cross contamination. The sample gross weight is measured, and the blank sample is processed as an actual sample. Both filtration and evaporation methods are used in this quality-control test, depending on the method that is used at the time of processing.

After drying, the weight of the container (and filter, if applicable) is determined for the distilled-water sample blanks and compared to the original tare weight. The criterion for an acceptable deviation from a zero change in net weight is $\pm 0.0003 \mathrm{~g}$ (equivalent to $1 \mathrm{mg} / \mathrm{L}$ for a 300 - $\mathrm{mL}$ sample). If the change in the net weight of the sample blank exceeds the equivalent of $1 \mathrm{mg} / \mathrm{L}$, which represents the minimum reporting level for suspended-sediment concentration, the balance calibration is checked. If the balance is correctly reading a value $\pm 0.0003 \mathrm{~g}$, analytical procedures and previous results are reviewed to evaluate the need for additional testing or corrective actions. Adjustments to analytical results for the sediment samples are applied if the net sediment weight of the sample blanks equals or exceeds $0.0006 \mathrm{~g}$, which represents an equivalent concentration of $2 \mathrm{mg} / \mathrm{L}$ (twice the minimum reporting level.)

\section{Filter Blanks}

Filter blanks are used to identify systematic errors resulting specifically from loss of filter fiber during filtration of samples. Whereas sample blanks attempt to collectively identify errors for a series of processing steps, filter blanks define the probable magnitude of error associated with a single step in the analytical process. Potential loss of filter fiber is minimized by rinsing and seating filters in crucibles with distilled water under a vacuum. This seating procedure is performed after the cleaning process and is designed to remove loose fibers before drying and obtaining a crucible tare weight.

Two filter blanks are processed for every bench of samples when the filtration method is used. All data are recorded in a quality-control logbook. A container tare weight (with filter) is determined for each filter blank. A volume of $50 \mathrm{~mL}$ of distilled water (similar to the volume of a decanted sample) is poured into the crucible and vacuumed through the filter. The crucible is then dried in the same manner as routine samples. After drying and cooling, the crucibles are placed in desiccators. Final weights are obtained and recorded, then compared to the original tare weights. Consistent weight losses of $0.0003 \mathrm{~g}$ or greater indicate a potential problem that requires additional testing and evaluation for corrective action.

\section{Field Replicates}

Field replicates can be obtained in different ways to provide an assessment of precision (reproducibility) of analytical results. Replicate samples are two or more samples 
considered to be essentially identical in composition. Replicate samples can be obtained in the field by either repeating the collection process to obtain two or more independent composite samples or by splitting a single composite sample into two or more subsamples. The individual replicate samples are then analyzed separately.

Precision of analytical results for field replicates are affected by numerous sources of variability within the field and laboratory environments which include variations in environmental conditions, sample collection, sample processing, and sample analysis. Because of the numerous sources of variability, if the concentrations determined for the replicate samples are within 10 percent of each other, the overall process of sample collection and analysis is considered to be acceptable.

\section{Method-Comparison Replicates}

To assess the comparability of results obtained by the filtration and evaporation methods, replicate samples with a known and identical sediment concentration are analyzed independently using each method (filtration and evaporation). Because several aspects of processing differ between the two methods, the resulting concentrations are compared to detect and quantify significant differences. The results also are compared to a theoretical concentration, based on the sample volume and sediment weight used to make the method-comparison replicate sample. Method comparisons are conducted twice annually.

For the methods-comparison test, three sets of four clean, glass-sample bottles are weighed to verify that the etched tare weights are correct. A volume of $300 \mathrm{~mL}$ of distilled water is added to each bottle. Identical weights of sediment are measured on dry, tared containers for each of three ranges of sediment weight. Sediment weights of 0.0010, 0.0300, and $0.1000 \mathrm{~g}$ are used to provide small, medium, and large concentrations of filterable sediment that represent a typical environmental range. The measured sediment is carefully transferred to the bottles. Sample gross weights are then measured and the three sets of quality-control samples are processed as routine samples by the two methods. For the three ranges of sediment weight, two bottles are processed by each method to provide duplicate results within and between the methods. Because distilled water is used, quality-control samples processed by the evaporation method do not require a dissolved-solids correction.

After drying and determining the sediment net weight, concentrations are calculated for each quality-control sample. The method comparison is considered acceptable if the concentrations determined by each method are within 5 percent of each other and the theoretical concentration. Concentrations of duplicate samples for each method are considered to have acceptable precision if the values are within 5 percent. If concentrations between or within methods differ by more than 5 percent, another set of method-comparison replicates is processed. If the second round of testing results in unacceptable method comparison or precision, procedures are reviewed to evaluate possible sources of the differences and corrective actions are implemented.

\section{Extracted Sample Water}

The overlying water that is decanted from the sample bottles (after the sediment has settled to the bottom) is collected in a large glass jug and disposed of when the bottle is full. If settling is complete within the sample bottles and decanting is done carefully, this decanted water will contain at most a negligible amount of sediment. Sample water that is vacuumed through crucible filters during the filtration process also is drained to the same collection jug. Improperly seated filters at the base of crucibles could allow sediment to pass by the sides of the filter. To verify that sediment is not lost during the decanting or filtration process, quality-control samples of the extracted sample water removed by the vacuum are periodically analyzed, typically twice yearly or when the water in the collection jug visually appears to be cloudy. The turbidity of the water is noted before each disposal to determine if additional testing is needed.

Duplicate samples of about $300 \mathrm{~mL}$ are poured from the collection jug after thorough agitation into tared glass sample bottles. The sample gross weights are measured and the entire $300-\mathrm{mL}$ sample volume is processed by the filtration method. The crucibles are dried and the sediment net weight is determined. Concentrations determined for samples of extracted water are considered to be acceptable if they do not exceed the minimum reporting level of $1 \mathrm{mg} / \mathrm{L}(0.0003 \mathrm{~g}$ per $300 \mathrm{~mL}$ of sample). If results are unacceptable, the process is evaluated and retested until acceptable results are achieved.

\section{External Testing}

Participation in external testing and laboratory reviews provides evidence that the Montana Sediment Laboratory procedures comply with standardized methods and that analytical results meet acceptance criteria. Results from testing are compared with other USGS sediment laboratories, and outside reviews provide guidance on established and emerging laboratory protocols.

\section{Sediment Laboratory Quality-Assurance Program}

The Sediment Laboratory Quality-Assurance (SLQA) program is implemented by the USGS Office of Water Quality and is designed to determine the bias and precision of sediment-concentration analyses determined by sediment laboratories of the USGS. Quality-assurance samples of known sediment concentration are distributed by the USGS Branch of Quality Systems to all USGS sediment laboratories (Gordon and Newland, 2000). The quality-assurance samples contain particle sizes ranging from sand to clay. The qualityassurance samples are analyzed by each laboratory using standard methods and the results are reported to the USGS 
Branch of Quality Systems. An inter-laboratory comparison of results is used to determine the bias and precision of results from the individual sediment laboratories. Results are distributed to each laboratory to indicate performance over the range of sediment concentrations tested. Laboratories with unacceptable performance results are required to conduct additional testing and might be required to submit to an onsite audit of laboratory equipment and procedures by the USGS Branch of Quality Systems.

\section{Laboratory Reviews}

All USGS sediment laboratories undergo a formal review of facilities and operations every 3 years. The review is conducted by a team of sediment specialists designated by the USGS Office of Surface Water. The review is designed to evaluate laboratory operations, identify deficiencies in procedures, and provide recommendations for correcting problems or improving quality. Quality-control logbooks are reviewed to evaluate documentation procedures and the performance of laboratory equipment.

\section{Data Management}

Determination of suspended-sediment concentration and particle-size distribution requires numerous tabulations of data and mathematical calculations. The accuracy of the data from the Montana Sediment Laboratory is systematically checked and the values are technically reviewed to assure that the data are reasonable for the prevailing hydrologic conditions and site characteristics. Analytical results in electronic databases and report manuscripts are verified prior to public release of sediment data.

\section{Laboratory-Data Files}

All data generated during the sequence of steps from sample collection through analysis are stored in various files that permit the tracking, retrieval, storage, and transmittal of data. The files consist of electronic data and original documents and forms. Electronic data are retrieved as paper copy and filed.

Data entered in the computer during laboratory analysis are stored in electronic files generated by the SLEDS program. These data are retrievable by a laboratory-identification number assigned to each sample. Paper copies of the analytical results are stored in the Center in both the water-quality station files and the Montana Sediment Laboratory files.

The analytical progress of samples collected by USGS personnel and observers at daily sediment stations is tracked using a sediment-data distribution form (fig. 11). This form is used to record sample-collection dates, sample type, and completion status of laboratory analysis, including the dates of shipment and receipt of analytical results for samples sent to the Iowa Sediment Laboratory. Subsequent distribution of laboratory data to the computation folders maintained by field offices, water-quality files in the Center's Data Management Unit, and cooperating agencies also is documented on this form.

The potential loss of sediment data from either electronic or paper files requires that a duplicate copy of both be kept in paper files. Paper copies of all electronic and laboratory-data forms are stored at separate locations in at least two independent files. Copies, rather than original documents, are mailed from the laboratory in response to data requests.

Data entered into the computer are subject to damage or loss during power failure or equipment malfunction. Losses are minimized by nightly backup of the SLEDS database. The tapes are on a monthly rotation with the first day-of-the-month tape saved for 2 years. Tapes that are saved in January and July are archived.

\section{Data Review}

The quality of suspended-sediment data generated by the Montana Sediment Laboratory is maintained by following the procedures described in this report and by performing a systematic review of analytical results before data release. The systematic review includes checks of all manual calculations and periodic checks of the SLEDS computer-program algorithms. In addition, data for individual steps of the analytical sequence are checked when analytical results appear erroneous. Although quality-control measures integrated into the analytical sequence are designed to minimize systematic errors, all random errors cannot be prevented. Therefore, additional review of the data in a hydrologic context can identify questionable values that need to be further evaluated. For any unusual values, the sediment container is inspected and, in some instances, reweighed to verify the original results. Remarks on field forms that note the sampler's observations of stream conditions also are inspected for further verification. If adequate verification of unusual values is not possible, the analytical result is not approved and is not entered in the Center's water-quality database.

Manual calculations of concentration and particle-size distribution made by the laboratory analyst are verified by an independent checker. The verification applies to all sample data that are recorded. The manual calculations used to determine the final results are noted directly on the laboratory analysis form. If corrections are not necessary, the checker initials the analysis form and routes it to the laboratory supervisor. If corrections are necessary, the original value is crossed out and the correct value is written above the original entry; the correction is initialed and the analysis form is then routed to the laboratory supervisor for final review.

Calculations by the SLEDS program are periodically checked to ensure that automatic computations are correct. On a quarterly basis, data for selected samples are manually calculated to determine sediment concentration, corrections for dissolved-solids concentration, and conversion from parts per million to milligrams per liter. Results of these calculations are 

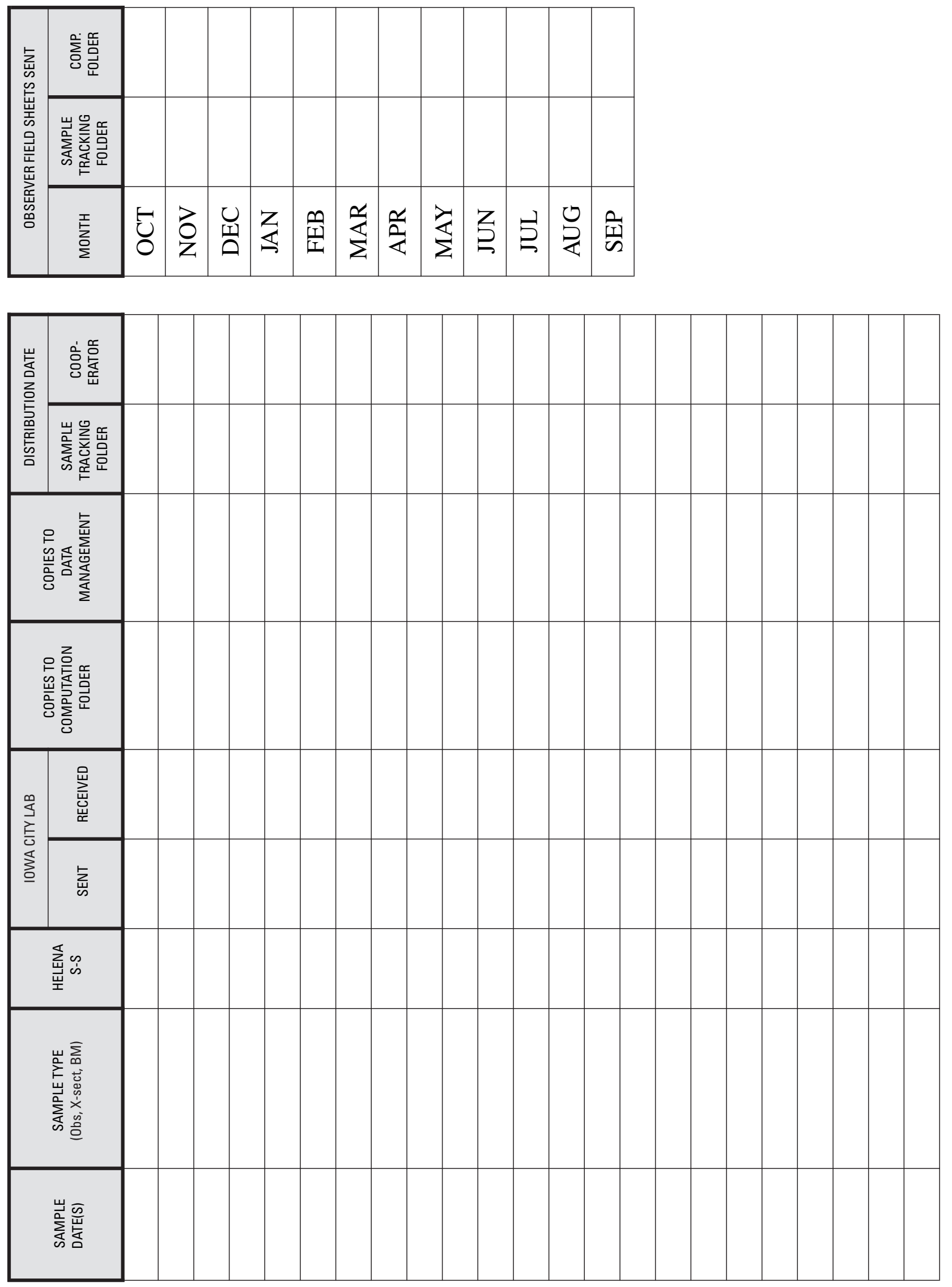

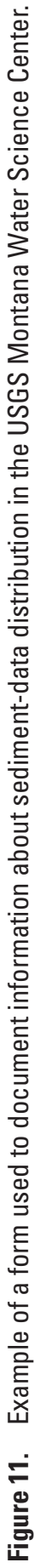


compared to values calculated by SLEDS to verify accuracy. Discrepancies between SLEDS and manual results are brought to the attention of the Center's Information Technology Specialist, who evaluates the extent of the discrepancy.

The final step before approval of laboratory data for transmittal to the Center's water-quality database or daily sediment computation folders is a technical review by the laboratory supervisor. Concentration and particle-size data for all samples are reviewed to verify completeness, proper computational procedure, adequate documentation when routine procedures are changed, consistency of results for all quality-control samples, and hydrologically reasonable values. The data are retrieved after transmittal of the SLEDS data files into the Center's water-quality database and verified by comparison to original documents.

Final approval of the sediment data in the water-quality database is completed by the Center Water-Quality Specialist, typically at the end of a water year when all water-quality, sediment, and hydrologic data are reviewed. After final approval, the Data Management Unit transfers the Center water-quality data files to the National Water Information System (NWIS) of the USGS where the sediment data can be accessed along with corresponding water-quality data collected concurrently with the suspended-sediment sample. These data can be accessed at http://waterdata.usgs.gov/mt/ nwis/.

\section{Publication}

Sediment data that have been approved for release are compiled and published annually by the Center in the report series "Water Resources Data, Montana" (U.S. Geological Survey, issued annually). Montana Sediment Laboratory data published in these reports include instantaneous suspended-sediment concentration and particle-size distribution (suspended-sediment percent finer than $0.062 \mathrm{~mm}$ ) for periodic cross-sectional samples collected by USGS personnel. Sediment data for single-vertical samples collected by observers are not published, but are used to compute daily mean suspended-sediment concentrations at daily sediment stations using procedures described by Porterfield (1972). Values approved for publication are verified before printing the annual report.

\section{Summary}

The quality-assurance plan for the analysis of suspendedsediment samples by the USGS Montana Water Science Center Sediment Laboratory describes the quality-assurance policies and procedures to assure the quality of analytical results. Policies include requirements and guidelines for sediment-laboratory certification, personnel responsibilities and training, documentation requirements, and laboratory safety. All individuals involved in the processing and management of sediment data are required to adhere to designated practices and policies.

Quality-assurance procedures for processing suspendedsediment samples include the acquisition and maintenance of laboratory equipment and supplies. Sample management and analysis relies on strict adherence to procedures that follow established guidelines for analytical procedures and qualitycontrol testing. Data management requires accurate documentation of samples from the time of collection through final review and approval of analytical results.

\section{References Cited}

Edwards, T.K., and Glysson, G.D., 1999, Fields methods for measurement of fluvial sediment: U.S. Geological Survey Techniques of Water-Resources Investigations, book 3, chap. C2, 89 p. [Available online at http://water.usgs.gov/ pubs/twri/]

Gordon, J.D., and Newland, C.A., 2000, U.S. Geological Survey quality-assurance project for sediment analysis: U.S. Geological Survey Fact Sheet 031-00, 4 p.

Guy, H.P., 1969, Laboratory theory and methods for sediment analysis: U.S. Geological Survey Techniques of WaterResources Investigations, book 5, chap. C1, 58 p. [Available online at http://water.usgs.gov/pubs/twri/]

Guy, H.P., and Norman, V.W., 1970, Field methods for measurement of fluvial sediment: U.S. Geological Survey Techniques of Water-Resources Investigations, book 3, chap. C2, 59 p. [Available online at http://water.usgs.gov/pubs/twri/] 
Knapton, J.R., and Nimick, D.A., 1991, Quality assurance for water-quality activities of the U.S. Geological Survey in Montana: U.S. Geological Survey Open-File Report 91-216, $41 \mathrm{p}$.

Knott, J.M., Sholar, C.J., and Matthes, W.J., 1992, Quality assurance guidelines for the analysis of sediment concentration by U.S. Geological Survey sediment laboratories: U.S. Geological Survey Open-File Report 92-33, 22 p.

Lambing, J.H., and Dodge, K.A., 1993, Quality assurance for laboratory analysis of suspended-sediment samples by the U.S. Geological Survey in Montana: U.S. Geological Survey Open-File Report 93-131, 34 p.

Matthes, W.J., Jr., Sholar, C.J., and George, J.R., 1992, Quality assurance plan for the analysis of fluvial sediment by laboratories of the U.S. Geological Survey: U.S. Geological Survey Open-File Report 91-467, 31 p.

Moreland, J.A., 1995, Quality-assurance plan for waterresources activities in Montana-1995: U.S. Geological Survey Open-File Report 91-194 rev., 23 p.

Porterfield, George, 1972, Computation of fluvial-sediment discharge: U.S. Geological Survey Techniques of WaterResources Investigations, book 3, chap. C3, 66 p. [Available online at http://water.usgs.gov/pubs/twri/]

Skinner, E.L., Watterson, C.A., and Chemerys, J.C., 1983, Laboratory safety handbook: U.S. Geological Survey OpenFile Report 83-131, 52 p.

U.S. Geological Survey, issued annually, Water resources data, Montana: U.S. Geological Survey Water-Data Report. [Selected reports available online at http://pubs.usgs.gov/ $w d r / \# M T /]$

U.S. Geological Survey [variously dated], National field manual for the collection of water-quality data: U.S. Geological Survey Techniques of Water-Resources Investigations, book 9, chaps. A1-A9. [Available online at http://pubs.water.usgs. gov/twri9A/]

U.S. Geological Survey [no date], Sediment Laboratory Environmental Data System training manual: $45 \mathrm{p}$.

U.S. Geological Survey Memorandum (public access) Office of Surface Water Technical Memorandum 91.11, August 14, 1991, Certification training for sediment laboratories. [Available from the U.S. Geological Survey at $h t t p: / / w a t e r$. usgs.gov/admin/memo/SW/sw91.11.html] 
For additional information contact:

Director, Montana Water Science Center U.S. Geological Survey

3162 Bozeman Avenue

Helena, Montana 59601

Telephone: 1-406-457-5900

World Wide Web: http://mt.water.usgs.gov/ 
